\title{
Review
}

\section{Some Heteroaromatic Organomercurials, Their Syntheses and Reactions: A Review of Our Research (1980-2000)}

\author{
Lech Skulski* and Piotr Wroczynski* \\ Chair and Laboratory of Organic Chemistry (L.S.) and Department of Physical Chemistry \\ (P.W.), Faculty of Pharmacy, Medical University, PL 02-097 Warsaw, Poland, Banacha 1. \\ Tel./Fax: +(48) 22-8226843.
}

*To whom the correspondence should be addressed; E-mail: 1skulski@farm.amwaw.edu.pl or wropio@farm.amwaw.edu.pl

Received: 1 October 2001 / Accepted 24 October 2001 / Published: 30 November 2001

\begin{abstract}
This review reports some novel (or improved) synthetic methods for preparing a number of aromatic (carbocyclic and predominantly heterocyclic) organomercurials, particularly those derived from theophylline, theobromine and uracil, as well as some novel halo- and cyano-demercuration reactions. We have also synthesized the first stable organic derivative of mercury(I), viz. 1,8-bis(acetoxydimercurio)theobromine, and studied its novel reactions. We have also improved the old Willgerodt method (1897), applicable for preparing various diaryliodonium chlorides from appropriate (dichloroiodo)arenes and symmetric aromatic mercurials. A full list of our works, published over the past twenty years (1980-2000), is also provided (see Refs. 1-16).
\end{abstract}

Keywords: heteroaromatic organomercurials, halo-demercuration reactions, cyanodemercuration reaction, heteroaromatic halides and nitriles 


\section{Contents}

1. Introduction

2. Early Results: 8-Substituted Caffeine Mercurials and Their Demercuration Reactions

2.1. Halo-demercuration Reactions of Caffeine Mercurials

2.2. Cyano-demercuration Reaction of Caffeine Mercurials

2.3. Unsuccessful Reactions with Caffeine Mercurials and Conclusions

3. "Model" Monosubstituted Benzene Mercurials and Their Demercuration Reactions

4. "Model" 2-Substituted Furan and Thiophene Mercurials and Their Demercuration Reactions

5. 6-Substituted 2,3-Diphenyl-5-methoxybenzo[b]furan Mercurials and Their Demercuration Reactions

6. 5-Substituted 1,3-Dimethyluracil and 1-Methyluracil Mercurials and Their Demercuration Reactions

7. 5-Substituted 2,4-Dimethoxypyrimidine Mercurials and Their Demercuration Reactions as well as an Indirect Method for Preparing 5-Halogeno-substituted Uracils

8. 5-Substituted Uracil Mercurials and Their Demercuration Reactions

9. 8-Substituted Theophilline Mercurials and Their Demercuration Reactions

10. 8-Substituted Theobromine Mercurials and Their Demercuration Reactions

11. Preparation of 1,8-bis(Acetoxydimercurio)theobromine and Its Reactions

12. Further Studies on Some Heteroaromatic Mercurials

13. Final Results of Our Halo- and Cyano-demercuration Reactions

13.1. Aromatic Iodides from Aromatic Organomercurials

13.2. Aromatic Bromides from Aromatic Organomercurials

13.3. Aromatic Chlorides from Aromatic Organomercurials

13.4. Aromatic Fluorides from Aromatic Organomercurials

13.5. Aromatic Nitriles from Aromatic Organomercurials

14. Improved Syntheses of Some Diaryliodonium Salts from Symmetric Diarylmercurials and (Dichloroiodo)arenes (Willgerodt's method)

15. Conclusions

\section{Introduction}

The first organomercury(II) compound (organomercurial) was reported by E. Frankland (1850), who synthesized dimethylmercury, $\mathrm{Me}_{2} \mathrm{Hg}$, by the action of methyl iodide on mercury metal under sunlight irradiation. The number of structurally diverse organomercurials that were later synthesized for pharmacological purposes is very large, but their role in chemotherapy has now been completely superseded and their applications as fungicides are also on the decline, owing to their toxicity towards human beings and animals. Nevertheless, numerous organomercurials have found increasing applications as useful reagents for the synthesis of many other organometallics via metal exchange reactions, and they are still attractive as synthetic intermediates which are usually readily available, 
accommodate essentially all functional groups and possess remarkable thermal and chemical stability towards air, water, dilute acids and bases. These valuable features allow synthetic reactions employing organomercurials to be run under a wide variety of reaction conditions. The major disadvantage of these compounds is the high toxicity of more volatile mercurials. In fact, all heterocyclic (lactamic) organomercurials prepared by us during the course of our research (1980-2000) were nonvolatile and either slightly soluble or practically insoluble in common solvents, hence they were notably less hazardous than e.g. many aliphatic organomercurials. However, due to their very limited solubility in boiling common solvents, they often could not be purified satisfactorily or not be purified at all. This made it difficult (or even impossible) to analyze them reliably for the purpose of making proper structural assignments. Therefore, their possible structures were deduced from subsequent, well known and effective, chemical reactions (usually iodo-demercuration and/or bromo-demercuration reactions) followed by chemical and spectral analysis of the resulting products (i.e. monoiodo and/or monobromo derivatives of the parent aromatics), often also produced in the other known routes, for the sake of a better comparison.

There are a large number of different methods for preparing unsymmetric aromatic organomercurials, ArHgX, but the direct mercuration of aromatic systems is evidently the most simple of them and is thus very often used. Its proper and effective application strongly depends on: (i) the relative reactivity of the reacted aromatic system towards the electrophilic attack by a mercuric salt; (ii) the relative electrophilicity of the mercuric salt applied, e.g. $\mathrm{HgCl}_{2}<\mathrm{Hg}\left(\mathrm{OCOCH}_{3}\right)_{2}<$ $\mathrm{Hg}\left(\mathrm{OCOCF}_{3}\right)_{2}<\mathrm{Hg}\left(\mathrm{ClO}_{4}\right)_{2}$; (iii) the applied reaction conditions: the use of a proper solvent, temperature and reaction time. This is an ordinary electrophilic aromatic substitution and takes place via the arenium ion mechanism to form the corresponding unsymmetric aromatic mercurials, e.g. $\mathrm{ArHgCl}<\mathrm{ArHgOCOCH}_{3}<\mathrm{ArHgOCOCF}_{3}<\mathrm{ArHgClO}_{4}$ (their relative reactivities towards the subsequent reactions with various electrophilic reagents being precisely in this order).

Although more or less effective depending on the particular case considered, several symmetrization methods are known to convert unsymmetric compounds $\mathrm{ArHgX}$ to the corresponding symmetric ones, $\mathrm{Ar}_{2} \mathrm{Hg}$ (usually more reactive than $\mathrm{ArHgX}$ ). It must be borne in mind that the following equilibrium should be displaced far to the right to cause effective symmetrization:

\section{Scheme 1}

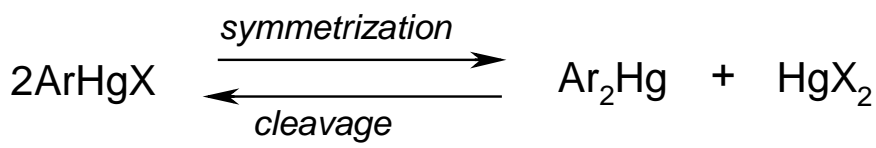

From a practical point of view, this may be attained either (i) by removal of the mercuric salt $\mathrm{HgX} \mathrm{X}_{2}$ by strong complexation with e.g. sodium or potassium iodide, sodium thiosulfate, ammonia or EDTA, potassium cyanide, potassium thiocyanate, etc. or (ii) by reduction of $\mathrm{HgX}_{2}$ with hydrazine, sodium stannite, by electrolysis, or otherwise. Consequently, there is no single general procedure applicable to effectively symmetrize the various types of $\mathrm{ArHgX}$, as certain types of $\mathrm{ArHgX}$ compounds are symmetrized with great ease and give high yields of $\mathrm{Ar}_{2} \mathrm{Hg}$, while others are resistant to particular 
symmetrization agents, and the desirable $\mathrm{Ar}_{2} \mathrm{Hg}$ can only be obtained by changes in the applied procedure(s).

In 1979, when we started our preliminary experiments in this area, the direct mercuration with mercuric salts of some important "model" lactamic heterocycles, e.g. uracil, theobromine and theophylline, had not been previously reported in the literature. The attempted mercuration reactions of these compounds at their $\mathrm{C}_{5}$ or $\mathrm{C}_{8}$ positions, respectively, resulted only in the formation of their insoluble $\mathrm{N}-\mathrm{Hg}$ salts $\mathbf{1}$ - 3 (named also 1:1 or 1:2 mercuric "complexes"), which were precipitated out in full from the mercurating reaction mixtures - this impeded attempts to obtain their true organomercurials, i.e. their mercurated derivatives with the mercury atom joined to the organic residues via $\mathrm{C}_{5}$ or $\mathrm{C}_{8}$ carbon atoms.

Scheme 2<smiles>O=c1ccn2c(n1)O[Hg]2</smiles>

a $1: 1 \mathrm{Hg}$ mercuric complex ( $\mathrm{N}-\mathrm{Hg}$ salt)<smiles>Cn1c(=O)c2c(ncn2C)n(C)c1=O</smiles><smiles>Cn1c(=O)c2c(ncn2C)n(C)c1=O</smiles>

2:1 Hg mercuric complexes ( $\mathrm{N}-\mathrm{Hg}$ salts)

In contrast, heterocycles devoid of any acidic N-H group(s), e.g. caffeine (see Section 2), 1,3dimethyluracil (see Section 6), 2,4-dimethoxypyrimidine (see Section 7), or 2,3-diphenyl-5-methoxybenzo[b]furan (see Section 5) were readily mercurated directly to form the respective unsymmetric organomercurials, $\mathrm{ArHgX}$, which were often symmetrized to form $\mathrm{Ar}_{2} \mathrm{Hg}$. Next, the mercurials of the two types were always iodo-demercurated and/or bromo-demercurated to form the corresponding iodides or bromides, ArI or ArBr, which after their purification were analyzed and studied by ${ }^{1} \mathrm{H}-\mathrm{NMR}$ and other techniques to confirm the chemical structures of the starting mercurials.

Generally, it is known that mercury(II) ions, consistent with their pronounced electrophilic character, can effectively mercurate a large number of aromatics at their carbon atom(s) to form the corresponding true organomercurials if they are inherently devoid of any acidic S-H, O-H, N-H, $\mathrm{Se}-\mathrm{H}$, and sometimes $\mathrm{P}-\mathrm{H}$ groupings. Otherwise, $\mathrm{Hg}$ (II) ions reveal a greater tendency to combine with those electronegative heteroatoms bearing lone pair(s) of electrons, forming thus some seemingly 
"mercurated", sparingly soluble final products or intermediates - which are not true organomercurials, since the mercury atom therein is joined to the organic residue not via carbon atom but via the respective heteroatom. Those containing the $\mathrm{O}-\mathrm{Hg}$ bond are the least stable. Compounds with the $\mathrm{S}-\mathrm{Hg}$ linkage are formed very readily and exhibit particular stability. The strength of the $\mathrm{N}-\mathrm{Hg}$ bond varies between wide limits, but in most cases it does not exceed that of the $\mathrm{S}-\mathrm{Hg}$ bond. Organic compounds containing $\mathrm{O}-\mathrm{Hg}, \mathrm{N}-\mathrm{Hg}$, and sometimes even $\mathrm{S}-\mathrm{Hg}$ bonds are often the first intermediates formed during the direct mercurations of oxygen-, nitrogen-, and some sulfur-containing compounds, and are transformed more or less readily into compounds mercurated at the carbon atom (true organomercurials), when this process is carried out under more vigorous conditions, e.g. at a higher temperature or at a lower $\mathrm{pH}$. For example, thioanisole can be $\mathrm{C}$-mercurated in $36.6 \%$ yield by means of $\mathrm{Hg}\left(\mathrm{OCOCH}_{3}\right)_{2}$ on a steam bath, giving thus 4-(acetoxymercurio)thioanisole; for more such examples see Ref. 23, p. 93.

During the course of our systematic, multi-year studies of various aromatic (carbo- and predominantly heterocyclic) true organomercurials and their reactions, we successfully synthesized novel organomercurials derived from theobromine and theophylline (Sections 9 and 10), uracil (Section 8), and also some other mercurials, though mostly in indirect routes. We also isolated (in ca $28 \%$ yield) the supposed-to-be 1,8-bis(acetoxydimercurio)theobromine, which seemingly represents the first stable organic derivative of $\operatorname{mercury}(\mathbf{I})$, and we subsequently studied its chemical properties (Section 11). We also discovered several novel halo- and cyano-demercuration reactions; in our opinion, our novel fluoro-, chloro-, and cyano-demercuration reactions are particularly interesting and useful. We also extended, improved and better substantiated Willgerodt's old method (1897), which enables to synthesize diaryliodonium chlorides by reacting (dichloroiodo)arenes with symmetric aromatic organomercurials, in stirred hot aqueous suspensions (Section 14). For more information on our own published achievements [1-16] see the sections that follow.

\section{Early Results: 8-Substituted Caffeine Mercurials and Their Demercuration Reactions [1, 2,} 11 and 12]

Previously, Rosenthaler [43] had mercurated caffeine (4a) to afford 8-(acetoxymercurio)caffeine (4b) in $90 \%$ crude yield, on boiling 4 a for 48 hours with an aq. $\mathrm{Hg}\left(\mathrm{OCOCH}_{3}\right)_{2}$ solution acidified with $\mathrm{CH}_{3} \mathrm{CO}_{2} \mathrm{H}$. Next, he symmetrized $\mathbf{4 b}$ with a boiling aq. KI solution for 30 minutes, to give $8,8^{\prime}-$ mercuriobis(caffeine) (5) in 50\% crude yield; he did not carry out any further reactions with $\mathbf{4 b}$ and $\mathbf{5}$. In our laboratory, we improved the above synthesis of $\mathbf{4 b}$, by adding a few drops of conc. aq. $\mathrm{HClO}_{4}$, a recommended catalyst [23, 24, 26-28], to the mercurating reaction mixture, which shortened considerably the mercuration time to only four hours, while preserving the same $90 \%$ crude yield; we also established that the mercurating solutions may be prepared in situ by dissolving the freshly prepared yellow $\mathrm{HgO}$ in hot aq. $\mathrm{CH}_{3} \mathrm{CO}_{2} \mathrm{H}$. 


\section{Scheme 3}<smiles>[X]c1nc2c(c(=O)n(C)c(=O)n2C)n1C</smiles><smiles>Cn1c(=O)c2c(nc(O)n2C)n(C)c1=O</smiles>

$\mathrm{X}=\mathrm{H}(\mathbf{a}) ; \mathrm{HgOCOCH}_{3}(\mathbf{b}) ; \mathrm{I}(\mathbf{c}) ; \mathrm{Br}(\mathbf{d}) ; \mathrm{Cl}(\mathbf{e}) ; \mathrm{F}(\mathbf{f}) ; \mathrm{CN}(\mathbf{g})$.

We also improved the crude yield of the symmetrization of $\mathbf{4 b}$ from $50 \%$ to $83 \%$ by using a hot (ca. $90^{\circ} \mathrm{C}$ ) aqueous $\mathrm{Na}_{2} \mathrm{~S}_{2} \mathrm{O}_{3}$ solution, instead of aq. KI. We also metathesized $\mathbf{4 b}$ into sparingly soluble 8 -(chloromercurio)caffeine ( $83 \%$ crude yield) by adding excess aq. $\mathrm{NaCl}$ solution to a boiling solution of $\mathbf{4 b}$ in water $[1,11]$. On heating with an aq. $\mathrm{Na}_{2} \mathrm{~S}$ solution, the black precipitate of $\mathrm{HgS}$ conclusively proved the presence of mercury in the three aforementioned caffeine mercurials; their chemical structures were confirmed by their ${ }^{1} \mathrm{H}-\mathrm{NMR}$ solution spectra as compared with that of caffeine $[1,11]$, as well as by subsequent halo- and cyano-demercuration reactions discussed below (see also Ref. 11).

Finally, it should be recalled that our many attempts to synthesize either 8-(trichloroacetoxymercurio)caffeine or the more thermostable 8-(chloromercurio)caffeine by a one-pot method suitable for preparing the thermostable phenylmercury(II) chloride were without success: the latter benzene mercurial was obtained in $70 \%$ yield when yellow $\mathrm{HgO}$ and $\mathrm{CCl}_{3} \mathrm{CO}_{2} \mathrm{H}$ were stirred in thiophene-free benzene for ca one hour at $65-70^{\circ} \mathrm{C}$; for the explanation see Ref. 11 as well as Section 3.

\subsection{Halo-demercuration Reactions of Caffeine Mercurials [1, 2, 11 and 12]}

Gomberg [44] had reported the failure to iodinate caffeine (4a) with diiodine in chloroform; later on, 8-iodocaffeine (4c) was obtained in ca $40 \%$ yield by heating caffeine (4a) with diiodine in a sealed tube at $150^{\circ} \mathrm{C}$ [45]. In our laboratory, at first we iodo-demercurated caffeine mercurials $\mathbf{4 b}$ and $\mathbf{5}$ by applying a widely used procedure $[17,23-28]$; on heating these mercurials with hot $\left(80^{\circ} \mathrm{C}\right)$ aq. $\mathrm{KI}_{3}$ solutions for 30 minutes, we obtained $\mathbf{4 c}$ in the same $95 \%$ yield (after purification) from the both substrates $\mathbf{4 b}$ and $\mathbf{5}[1,2]$. Similarly, the sparingly soluble 8 -(chloromercurio) caffeine $(\mathbf{4}, \mathrm{X}=\mathrm{HgCl})$ was iodo-demercurated to give pure $\mathbf{4 c}$ in $65 \%$ yield [11]. The same pure $\mathbf{4 c}$ was also obtained by us $[1,2]$ in $90 \%$ yield from the both substrates $\mathbf{4 b}$ and $\mathbf{5}$, by heating them with a hot $\left(80^{\circ} \mathrm{C}\right)$ aq. solution of the freshly sublimated ICN [Caution: ICN is highly toxic]; in fact, it is an effective, though less convenient and unsafe, iodo-demercuration method.

Previously, caffeine (4a) was directly brominated to give 8-bromocaffeine (4d) in high yields [45, 46]. In our laboratory, the two mercurials $\mathbf{4 b}$ and 5 were effectively bromo-demercurated, by applying the widely-used procedure [17, 23-28]; the reactions took place in hot $\left(80^{\circ} \mathrm{C}\right)$ aq. $\mathrm{KBr}_{3} \mathrm{Solutions}$ 
previously adjusted to $\mathbf{p H ~ 7 , ~ f o r ~} 30$ minutes, to give $4 \mathbf{d}$ (purified) in the same $83 \%$ yields from the both substrates $\mathbf{4 b}$ and $\mathbf{5}$. We also bromo-demercurated $\mathbf{4 b}$ and $\mathbf{5}$ (at $60^{\circ} \mathrm{C}$, for 2 hours) with an aq. slurry of a labile complex (or adduct) of unknown composition, $(\mathbf{K B r} \cdot \mathbf{B r C N})_{\mathbf{x}}$ [Caution: highly toxic], obtained by adding $\mathrm{Br}_{2}$ to a cooled saturated aq. KCN solution [47]; this gave compound $\mathbf{4 d}$ (purified) in $85 \%$ yields from the both substrates $\mathbf{4 b}$ and $\mathbf{5}$. In fact, this represents an effective, albeit less convenient and unsafe, novel bromo-demercuration method.

The direct chlorination of caffeine (4a) to 8-chlorocaffeine (4e) had been reported as early as 1850 ; fairly high yields of $4 \mathbf{e}$ (ca $80 \%$ ) were later reported in the literature [45, 48]. In our laboratory, we obtained the purified compound $4 \mathbf{e}$ in $27-90 \%$ yields, but only from the more reactive symmetric mercurial $\mathbf{5}$ [mercurial $\mathbf{4 b}$ did not react under the same reaction conditions]. At first, we reacted $\mathbf{5}$ with neat liquid $\mathbf{S}_{\mathbf{2}} \mathbf{C l}_{\mathbf{2}}$ or $\mathbf{S C l}_{\mathbf{2}}$ at room temperature for 4 hours to afford $4 \mathbf{e}$ in $80 \%$ or $70 \%$ yields, respectively; though the yield of the latter reaction with $\mathrm{SCl}_{2}$ was lower, nevertheless the crude $4 \mathbf{e}$ thus obtained was easier to purify. When mercurial $\mathbf{5}$ was similarly suspended in neat boiling $\mathbf{S O}_{\mathbf{2}} \mathbf{C l}_{\mathbf{2}}$ for 2 hours, then compound $\mathbf{4 e}$ (after its isolation and purification) was obtained in only $27 \%$ yield. These novel chloro-demercuration methods were later on also applied by us to other mercurials (Section 13.3). Finally, we must admit that we failed to obtain compound $4 \mathbf{e}$ upon passing gaseous $\mathrm{Cl}_{2}$ through solutions or suspensions of mercurials $\mathbf{4 b}$ or $\mathbf{5}$ in water, aq. $\mathrm{KCl}$ solutions, formamide, dimethyl sulfoxide, benzene, etc. The same was true for the action of chlorine in statu nascendi (generated in reaction: $6 \mathrm{HCl}+2 \mathrm{KClO}_{3} \rightarrow 6 \mathrm{Cl}+2 \mathrm{KCl}+3 \mathrm{H}_{2} \mathrm{O}$ ) upon $\mathbf{4 b}$ or $\mathbf{5}$ in aqueous media. For some more reactive organomercurials these chloro-demercuration reactions were successful [17, 23, 24, 26, 28]; see also Section 3.

8-Fluorocaffeine (4f) was not reported in the literature before 1981/1982 [1, 2]; until then very few organomercurials have been fluoro-demercurated, but only with difluorine diluted with nitrogen gas [26]. In our laboratory, we suspended the more reactive mercurial 5 [mercurial $\mathbf{4 b}$ did not react under the same reaction conditions] in liquefied, neat $\mathbf{S F}_{4}$ (b.p. $-40.4^{\circ} \mathrm{C}$. Caution: highly toxic) at $-70^{\circ} \mathrm{C}$ (solid $\mathrm{CO}_{2}+$ acetone) for 16 hours. After evaporating $\mathrm{SF}_{4}$, crude $4 \mathbf{f}$ was purified to give $30 \%$ yield (after 8 hours only 15\%); an increase in the reaction temperature (in an autoclave) considerably diminished the given yield. This novel and interesting fluoro-demercuration reaction was later on applied in our laboratory to other symmetric mercurials; see Ref. 12, where we summarized and commented all our fluoro-demercuration experiments; see also Section 13.4.

\subsection{Cyano-demercuration Reaction of Caffeine Mercurials [1,2]}

Previously, 8-bromocaffeine (4d) in the presence of $\mathrm{KCN}$ in $80 \%$ ethanol yielded caffeine-8carboxamide, which by treatment with $\mathrm{POCl}_{3}$ yielded 8 -cyanocaffeine $(\mathbf{4 g})[45,49]$; it is worth mentioning that $\mathrm{ICN}$, when reacted at $110^{\circ} \mathrm{C}$ with dimethylmercury, yielded mercuric iodide and methyl isocyanide [50]. In our laboratory, we reacted the more reactive, symmetric mercurial 5 with freshly purified $\mathrm{BrCN}$ [Caution: highly toxic] in water, at $60^{\circ} \mathrm{C}$ for 2 hours (at higher temperatures some decomposition of 5 was observed, whereas at $40^{\circ} \mathrm{C}$ the reaction did not proceed); after purification of the crude product, we obtained pure $\mathbf{4 g}$ in $50 \%$ yield; the same reaction with 
unsymmetric mercurial $\mathbf{4 b}$ gave pure compound $\mathbf{4 g}$ in only $25 \%$ yield. It was surprising that by using aq. $\mathrm{KBr}$ solutions instead of pure water for dissolving $\mathrm{BrCN}$, the same compound $\mathbf{4 g}$ was obtained, instead of the expected $\mathbf{4 d}$ (vide supra). By using aq. $\mathrm{KCN}$ solutions instead of water for dissolving $\mathrm{BrCN}$, the yield of this cyano-demercuration reaction was evidently lowered. We applied this interesting but unsafe reaction also for more reactive "model" benzene mercurials (see Section 3). It should be noted that when we reacted $\mathbf{4 b}$ or $\mathbf{5}$, under widely varied conditions, with $(\mathrm{CN})_{2}$ or $\mathrm{ClCN}$ solutions, we failed to obtain compound $\mathbf{4 g}$; the latter reagent decomposed vigorously both $\mathbf{4 b}$ and $\mathbf{5}$ in their solutions or suspensions.

\subsection{Unsuccessful Reactions with Caffeine Mercurials and Conclusions [1,2]}

The preparative demercuration methods discussed above show the usefulness of organomercurials in organic synthesis. There are, however, noticeable differences in the reactivity of the various organomercurials. It has been mentioned several times in the literature [23-28, 34] that $\mathrm{Ar}_{2} \mathrm{Hg}$ compounds are usually more reactive as compared with $\mathrm{ArHgX}$. It is seen that unsymmetric mercurial 4b does not react with $\mathrm{S}_{2} \mathrm{Cl}_{2}, \mathrm{SCl}_{2}, \mathrm{SO}_{2} \mathrm{Cl}_{2}$, and $\mathrm{SF}_{4}$ under the same experimental conditions as does symmetric $\mathbf{5}$. The cyano-demercuration reaction of symmetric mercurial $\mathbf{5}$ furnished twice as much of $\mathbf{4 g}$ as compared with unsymmetric mercurial $\mathbf{4 b}$. Only the iodo- and bromo-demercuration reactions furnished the same yields of $\mathbf{4 c}$ and $\mathbf{4 d}$ from both $\mathbf{4 b}$ and $\mathbf{5}$. We have also established experimentally that both 4b and 5 did not undergo several well-known demercuration reactions [23-28, 34] with $\mathrm{HNO}_{3},(\mathrm{CN})_{2},(\mathrm{SCN})_{2}, \mathrm{Cl}_{2}$ or chlorine in statu nascendi, $\mathrm{SOCl}_{2}$, and aryldiazonium cations, which were successful with some other, more reactive, organomercurials. Thus, it seems to us that both the caffeine mercurials $\mathbf{4 b}$ and $\mathbf{5}$ are noticeably less reactive in a number of demercuration reactions as compared with some corresponding organomercurials, $\mathrm{ArHgX}$ or $\mathrm{Ar}_{2} \mathrm{Hg}$, in which Ar represent e.g. $o$-nitrophenyl, thienyl or furyl moieties [23-28, 34]; cf. particularly our results presented in Sections 3 and 4.

3. "Model" Monosubstituted Benzene Mercurials and Their Demercuration Reactions [7, 11 and 12]

A survey of methods applied so far for the halo-demercuration of various organomercurials [17, 24-28, 34] reveals that dihalogens do decompose them in two stages: (1) $\mathrm{R}_{2} \mathrm{Hg}+\mathrm{X}_{2} \rightarrow \mathrm{RHgX}+\mathrm{RX}$, followed (with an excess of halogens) by (2) $\mathrm{RHgX}+\mathrm{X}_{2} \rightarrow \mathrm{R}-\mathrm{X}+\mathrm{HgX}_{2}$; it has been pointed out [23] that symmetric $\mathrm{R}_{2} \mathrm{Hg}$ react more readily than $\mathrm{RHgX}$. In 1870 Dreher and Otto [51] reacted cold solutions of diphenylmercury, $\mathrm{Ph}_{2} \mathrm{Hg}$ (in ethanol or better in $\mathrm{CS}_{2}$ ), with equimolar amounts of $\mathrm{I}_{2}$ or $\mathrm{Br}_{2}$, and they obtained the respective halogenomercurio- or halogeno-benzenes, whereas with an excess of the halogens the former were changed into the respective halogenobenzenes and mercuric salts (with necessary heating).

Dry dichlorine gives a vigorous reaction with $\mathrm{Ph}_{2} \mathrm{Hg}$ yielding $\mathrm{PhHgCl}, \mathrm{PhCl}$ and $\mathrm{HgCl}_{2}$; when $\mathrm{Cl}_{2}$ is bubbled through a hot aq. suspension of $\mathrm{Ph}_{2} \mathrm{Hg}$ or (better) through its hot solution in $\mathrm{CS}_{2}$, at first 
$\mathrm{PhHgCl}$, and then more and more $\mathrm{PhCl}$ and $\mathrm{HgCl}_{2}$ are obtained. The German authors [51] have also remarked that $\mathrm{PhHgCl}$ seems to be less reactive towards the action of $\mathrm{Cl}_{2}$ than the corresponding $\mathrm{PhHgBr}$ and $\mathrm{PhHgI}$ towards the action of $\mathrm{Br}_{2}$ and $\mathrm{I}_{2}$. A concentrated solution of hypochlorous acid acts like free $\mathrm{Cl}_{2}$, forming $\mathrm{PhHgCl}$ and $\mathrm{PhCl}$ from $\mathrm{Ph}_{2} \mathrm{Hg}$. An aqueous solution of $\mathrm{PhHgOCOCH}_{3}$ heated with an excess of $\mathrm{I}_{2}$ gives $\mathrm{PhI}, \mathrm{HgI}_{2}$ and $\mathrm{CH}_{3} \mathrm{CO}_{2} \mathrm{H}$ [51].

Later on, the iodo- and the bromo-demercuration reactions have vastly been improved [24-28, 34, 52], e.g. by using $\mathrm{KI}_{3}$ or $\mathrm{KBr}_{3}$ solutions, mostly aqueous (cf. Ref. 2), but also with a wide variety of solvents, e.g. alcohols, acetonitrile, DMF, DMSO, pyridine, dioxane or their mixtures with water. Even permercurated arenes are readily cleaved in this way [52] by $\mathrm{NaI}_{3}$ in $\mathrm{DMF}$ at room temperature for 3-14 days, by $\mathrm{KBr}_{3}$ aq. methanolic solutions at room temperature for $1-24$ hours, or by $\mathrm{Cl}_{2}$ in DMF at room temperature for 3-8 hours, giving thus the respective periodo-, perbromo-, and perchloro-arenes in good yields. It is also necessary to recall that on a prolonged heating $\mathrm{Ph}_{2} \mathrm{Hg}$ with $\mathrm{TeCl}_{2}$, mercuric telluride and $\mathrm{PhCl}$ are formed unexpectedly [23, 53]. Iodine monochloride reacts according to the reactions: $\mathrm{R}_{2} \mathrm{Hg}+2 \mathrm{ICl} \rightarrow 2 \mathrm{RI}+\mathrm{HgCl}_{2}$ and $\mathrm{RHgX}+\mathrm{ICl} \rightarrow \mathrm{RI}+\mathrm{HgXCl}[23,28]$; the same diiodocamphor is obtained when mercurated camphor reacts with $\mathrm{I}_{2}$ or with $\mathrm{ICl}$ or with $\mathrm{IBr}$ in benzene [17]. ICN acts preferably as a iodo-demercuration agent, whereas $\mathbf{B r C N}$ may act both as a bromo-demercuration agent as well as a cyano-demercuration agent depending on the reaction conditions (vide infra, as well as Section 2.2). $\mathrm{ClCN}$ has been reported to give no reaction at all with some organomercurials [17]; cf. however Section 2.2.

It is of interest to mention that ICN and $\mathrm{Me}_{2} \mathrm{Hg}$ in ethereal solution give $\mathrm{MeCN}$ at $50^{\circ} \mathrm{C}$, and $\mathrm{HgI}_{2}$ and methyl isonitrile at $110^{\circ} \mathrm{C}[17,23,50]$. It has also been reported [23] that $\mathbf{B r C N}$ does not cleave the $\mathrm{C}$-Hg bond, but only replaces e.g. the acetoxy group by bromine in $\alpha$-acetoxymercurio- $\beta$-methoxy$\beta$-phenylethane. Pseudohalogens, $\mathrm{X}_{2}=(\mathrm{CNS})_{2}$ and $(\mathrm{CN})_{2}$, do react with some symmetric organomercurials, $\mathrm{R}_{2} \mathrm{Hg}$, giving the respective $\mathrm{RX}$ and $\mathrm{RHgX}$ compounds; we failed, however, to replace mercury atoms in the less reactive caffeine mercurials on acting upon them with $(\mathrm{CNS})_{2}$ and $(\mathrm{CN})_{2}$ (see Ref. 2 as well as Section 2.3). The reaction with $\mathrm{ClN}_{3}$ undergoes similarly, viz. $\mathrm{R}_{2} \mathrm{Hg}+$ $\mathrm{ClN}_{3} \rightarrow \mathrm{RHgN}_{3}+\mathrm{RCl}$, and it was applied as well with $\mathrm{Ph}_{2} \mathrm{Hg}\left(\mathrm{R}=\mathrm{C}_{6} \mathrm{H}_{5}\right)[17,24-28,34]$.

\section{Scheme 4}

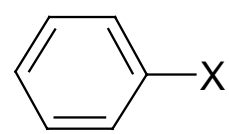

6

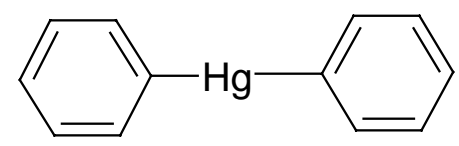

7

$\mathrm{X}=\mathrm{HgOCOCH}_{3}(\mathbf{a}) ; \mathrm{HgOCOCF}_{3}(\mathbf{b}) ; \mathrm{HgOCOCCl}_{3}(\mathbf{c}) ;$ $\mathrm{HgCl}(\mathbf{d}) ; \mathrm{I}(\mathbf{e}) ; \mathrm{Br}(\mathbf{f}) ; \mathrm{Cl}(\mathbf{g}) ; \mathrm{F}(\mathbf{h}) ; \mathrm{CN}(\mathbf{i})$.

In our next paper of the series [7], we reported the application of several halo- and cyanodemercuration procedures to the more reactive "model" benzene mercurials $6 \mathbf{a}, \mathbf{6 b}$ and 7 ; cf. our 
results discussed in Section 2. Thus, diphenylmercury, $\mathrm{Ph}_{2} \mathrm{Hg}$ (7), dissolved in ethanol smoothly gave only $\mathrm{PhI}(\mathbf{6 e})$ in $72 \%$ yield (purified product) on adding pure ICN and then refluxing the mixture for 3 hours. On refluxing for 3 hours a mixture of 7 with pure $\mathbf{B r C N}$ in benzene, only $\mathrm{PhCN}$ (6i) was produced in $86 \%$ yield - whereas when 7 was refluxed for 3 hours in an ethanolic solution containing $(\mathbf{B r C N} \cdot \mathbf{K B r})_{\mathbf{x}}$, a complex of unknown structure [47], only $\mathrm{PhBr}(\mathbf{6 f})$ was formed in $79 \%$ yield. The reaction of $\mathbf{7}$ with $\mathbf{C I C N}$, carried out under widely-varied experimental conditions, gave some composite mixtures, which were not subjected to closer study.

By reacting $\mathbf{7}$ with large excesses of neat liquid either $\mathbf{S}_{\mathbf{2}} \mathbf{C l}_{\mathbf{2}}$ or $\mathbf{S O}_{\mathbf{2}} \mathbf{C l}_{\mathbf{2}}\left[\mathbf{S C l}_{\mathbf{2}}\right.$ was not studied], and leaving overnight at room temperature, we obtained pure $\mathrm{PhCl}(\mathbf{6 g})$ in $78 \%$ or $47 \%$ yields, respectively. The former reaction was also carried out at first at $-10^{\circ} \mathrm{C}$, and next it was left overnight at room temperature: we obtained $\mathrm{PhCl}(\mathbf{6 g})$ in 35\% yield together with $30 \%$ of isolated $\mathrm{PhHgCl}$ (which throws some light on its mechanism). The second reaction was considerably accelerated by a FriedelCraft catalyst, viz. $\mathrm{AlCl}_{3}$. Both the symmetric mercurial $\mathbf{7}$ as well as the two unsymmetric ones, $\mathbf{6 a}$ and 6b, did react with an excess of neat $\mathrm{S}_{2} \mathrm{Cl}_{2}$ (under the same experimental conditions) to afford $\mathrm{PhCl}$ (6g) in 78\%, 50\% and 69\% yields, respectively; previously (Section 2), it was supposed that this new chloro-demercuration procedure was characteristic only of the symmetric organomercurials.

The novel fluoro-demercuration procedure, applicable only for the symmetric organomercurial 7, was reported in our other paper [12]; cf. also Section 2.1. On reacting 7 with a large excess of neat liquid $\mathrm{SF}_{4}$, for 8 hours at $-\left(60-70^{\circ} \mathrm{C}\right)$, it was possible to obtain $\mathrm{PhF}$ (6h; purified product) in $58 \%$ yield; its structure was confirmed by microanalyses and its ${ }^{1} \mathrm{H}-\mathrm{NMR}$ spectrum. In this publication we made the following remark (footnote on p. 26): "The calculated yields [for ArF] correspond to "ideal" reactions: $\mathrm{Ar}_{2} \mathrm{Hg}+\mathrm{SF}_{4} \rightarrow \mathrm{HgF}_{2}+2 \mathrm{ArF}$ (soluble in organic solvents; often volatile), whereas the "real" reactions probably are terminated either in full or in part at the intermediate stage yielding ArF $+\operatorname{ArHgF}$ (sparingly soluble in organic solvents; nonvolatile). Since the aim of our investigation [12] was to obtain the possible highest yields of ArF, therefore we did not scrutinize the nonextractable residues composed of mercuric salts heavily contaminated by some sulfur-containing side-products and, probably, by the less-reactive (under the given low-temperature conditions) fluoromercurials, ArHgF." In fact, all our fluoro-demercuration procedures, applicable only for $\mathrm{Ar}_{2} \mathrm{Hg}$ mercurials, resulted in moderate yields for the purified ArF, viz. 28-58\% [12].

In our next work [11] we attempted to mercurate benzene and caffeine by means of mercury(II) trichloroacetate; and we submitted therein a detailed review of the prior attempts to prepare this thermally unstable mercuric salt. We have come to the conclusion that it is reasonable to prepare this mercuric salt in situ to obtain appropriate mercurating reaction mixtures. When we suspended yellow $\mathrm{HgO}$ in thiophene-free benzene containing $\mathrm{Cl}_{3} \mathrm{CCO}_{2} \mathrm{H}$ (a 1:1 molar proportion of $\mathrm{Cl}_{3} \mathrm{CCO}_{2} \mathrm{H}$ to $\mathrm{HgO}$ seems to be optimal) and the reaction mixture thus obtained was heated for ca one hour at $65-70^{\circ} \mathrm{C}$, then we unexpectedly isolated $\mathrm{PhHgCl}(\mathbf{6 d})$ in $70 \%$ yield (purified product), instead of the thermolabile mercurial 6c. This method was quite unsuitable for the mercuration of less reactive caffeine. Next, mercurial $6 \mathbf{d}$ was readily iodo-demercurated to give $6 \mathbf{e}$ (purified product) in 59\% yield, with a hot $\left(80^{\circ} \mathrm{C}\right)$ aq. $\mathrm{KI}_{3}$ solution, for 30 minutes. 
4. "Model" 2-Substituted Furan and Thiophene Mercurials and Their Demercuration Reactions [5]

In order to extend the scope of the aforementioned (Sections 2 and 3) novel chloro-demercuration procedure [the action of neat, liquid $\mathbf{S}_{\mathbf{2}} \mathbf{C l}_{\mathbf{2}}$ on mostly symmetric organomercurials, yielding effectively the corresponding chloro derivatives, $\mathrm{ArCl}$; see however Section 3], we first synthesized (by the known methods) 2,2'-difurylmercury (8) and 2,2'-dithienylmercury (9) (Scheme 5).

We had expected in advance that they would be more reactive than those symmetric organomercurials discussed in Sections 2 and 3. However, in our attempted chloro-demercuration reactions we had to use only freshly-redistilled $\mathbf{S}_{\mathbf{2}} \mathbf{C l}_{\mathbf{2}}$ to remove the accompanying $\mathbf{S C l}$; the latter is known [54] to equilibrate as follows: $2 \mathrm{SCl}_{2} \rightrightarrows \mathrm{S}_{2} \mathrm{Cl}_{2}+\mathrm{Cl}_{2}$, which is very inconvenient due to the known high sensitivity of furan and thiophene towards the action of free dichlorine; see also our paper [5] where various chlorinating procedures applicable for furan and thiophene were briefly reviewed, with the relevant references.

\section{Scheme 5}
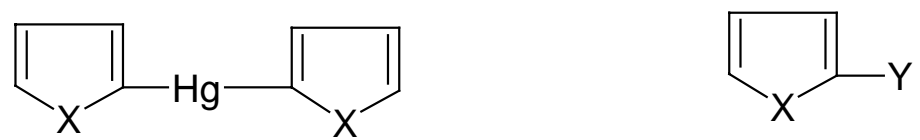

$\mathrm{X}=\mathrm{O}(\mathbf{8})$

$X=S(9)$;

$X=O, Y=C l(10 a) ; I(10 b) ;$

$\mathrm{X}=\mathrm{S}, \mathrm{Y}=\mathrm{Cl}(\mathbf{1 1} \mathbf{a}) ; \mathrm{I}(\mathbf{1 1} \mathbf{b})$;

At first, we reacted solid finely-powdered mercurials $\mathbf{8}$ or $\mathbf{9}$ as well as 2-(chloromercurio)furan or 2-(chloromercurio)thiophene with an excess, as previously (see Sections 2 and 3), of neat liquid $\mathbf{S}_{\mathbf{2}} \mathbf{C l}_{\mathbf{2}}$ with no solvent, over a wide temperature range from $-70^{\circ} \mathrm{C}$ up to room temperature. Even at $-70^{\circ} \mathrm{C}$ the reactions were extremely vigorous and could hardly be controlled. Colorless oils, in nearly quantitative yields, were isolated from the reaction mixtures, which were composite mixtures of several highly chlorinated compounds, in part also of open-ring structures, with only small admixtures of 2monochloro and 2,5-dichloro derivatives of furan or thiophene, respectively. After several attempts we achieved a proper and effective method of chloro-demercuration mercurials $\mathbf{8}$ and $\mathbf{9}$, but only using carbon disulfide as an inert diluent - the reactions were completed after two days either at room temperature with more reactive $\mathbf{8}$ or, with less reactive $\mathbf{9}$, on boiling under a reflux condenser; with still less reactive 2-(chloromercurio)furan or 2-(chloromercurio)thiophene the reactions did not proceed under the same experimental conditions. From the reaction mixtures we isolated either pure 2 chlorofuran (10a) in 60\% yield or pure 2-chlorothiophene (11a) in 70\% yield, with no trace of higherboiling 2,5-dichlorinated admixtures. Later on, we considerably simplified the syntheses of compounds 10a and 11a just by mixing together pure furan or thiophene with $\mathrm{HgCl}_{2}$ previously dissolved in an excess of the freshly-redistilled $\mathrm{S}_{2} \mathrm{Cl}_{2}$, followed by keeping the mixtures overnight at room temperature. Most likely, the reactions proceeded via some 2-mercurio intermediates, since no 2chloro derivatives were formed in the absence of $\mathrm{HgCl}_{2}$. From the reaction mixtures we isolated pure compounds 10a or 11a in $50 \%$ or $60 \%$ yields, respectively; see Ref. 5 for experimental details. 
The various methods for the direct iodination of furan and thiophene (and also other heterocycles) were very extensively reviewed in Ref. 55; they were also briefly reviewed in our paper [5]. We reacted symmetric mercurials $\mathbf{8}$ and $\mathbf{9}$ with the well-known [23, 26, 28, 34] iodo-demercuration agent, viz. an aq. $\mathrm{KI}_{3}$ solution, for 30 minutes at $80^{\circ} \mathrm{C}$, which gave pure $10 \mathrm{~b}$ or $11 \mathrm{~b}$ in $60 \%$ or $65 \%$ yields, respectively. These yields are considerably higher than those previously reported, when the same iododemercuration method was applied with either 2-(chloromercurio)furan (32\% yield was reported [56]) or 2-(chloromercurio)thiophene (a low yield was reported [57]). Our iodo-demercuration reactions confirmed the structures of the starting mercurials $\mathbf{8}$ and $\mathbf{9}$ as well as their higher reactivities as compared with the respective 2 -chloromercurio derivatives.

In our paper [5] we offered the following general remark (footnote on p. 445): "It is rather a common procedure that after completing several direct mercuration reactions with more electrophilic (than $\mathrm{HgCl}_{2}$ ) mercuric acetate or trifluoroacetate, the less soluble, but least reactive, chloromercurio derivatives are precipitated out with aq. $\mathrm{NaCl}$ or $\mathrm{CaCl}_{2}$ solutions, in order to increase the isolated yields of desirable mercurials. In our opinion, it is often more advantageous to collect the respective symmetric mercurials (usually less soluble as well), which may be obtained by subsequent additionif possible - of symmetrizing agents (e.g. $\mathrm{KI}, \mathrm{Na}_{2} \mathrm{~S}_{2} \mathrm{O}_{3}$, etc.) directly to the said reaction mixtures, and then to complete the symmetrization reaction in order to obtain the resulting, more reactive $\mathrm{Ar}-\mathrm{Hg}-\mathrm{Ar}$ compounds". In fact, we applied this approach in practice in our works [6] and [9]; see Sections 7 and 8 for details.

\section{6-Substituted 2,3-Diphenyl-5-methoxybenzo[b]furan Mercurials and Their Demercuration Reactions [10]}

Egyptian chemists [58] had synthesized a number of derivatives of heterocyclic compound 12a, and later they studied their biological activities. They established that in various reactions obeying the $\mathrm{S}_{\mathrm{E}}$-type mechanism, the respective derivatives of 12a were predominantly substituted at its $\mathrm{C}_{6}$ carbon atom. However, bromination of $\mathbf{1 2 a}$ with $\mathrm{Br}_{2}$ in $\mathrm{CCl}_{4}$ gave the 4,6-dibromo derivative of 12a. In cooperation with the Egyptian chemists we decided to synthesize in our laboratory the two mercurials $\mathbf{1 2 b}$ and $\mathbf{1 3}$ (Scheme 6), and then study their bromo- and iodo-demercuration reactions.

\section{Scheme 6}

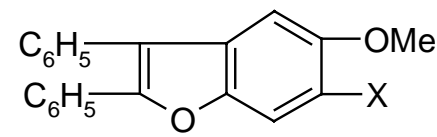

12

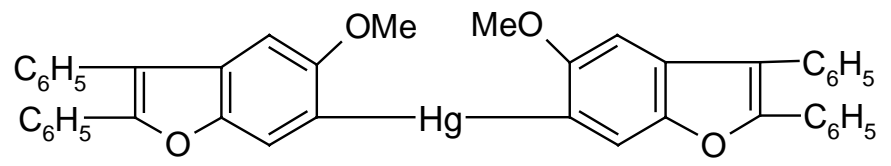

13

$$
X=\mathrm{H}(\mathbf{a}) ; \mathrm{HgOCOCH}_{3}(\mathbf{b}) ; \mathrm{I}(\mathbf{c}) ; \mathrm{Br}(\mathbf{d})
$$


The direct mercuration of 12a with $\mathrm{Hg}\left(\mathrm{OCOCH}_{3}\right)_{2}$ in boiling ethanol, for 2 hours, gave unsymmetric mercurial 12b in ca $70 \%$ crude yield, which next was readily symmetrized by a hot $\left(90^{\circ} \mathrm{C}\right) \mathrm{KI} / \mathrm{EtOH} / \mathrm{H}_{2} \mathrm{O}$ solution, for 2 hours, to afford symmetric mercurial $\mathbf{1 3}$ in $60 \%$ crude yield. Further proof of the structures of $\mathbf{1 2 b}$ and $\mathbf{1 3}$ was given by their routine bromo- and iododemercuration reactions, carried out for ca 30 minutes in hot $\left(80^{\circ} \mathrm{C}\right)$ aq. $\mathrm{KBr}_{3}$ or $\mathrm{KI}_{3}$ solutions, respectively. These two reactions furnished the respective 6-bromo or 6-iodo derivatives of 12a, i.e. pure compounds $\mathbf{1 2 c}$ and $\mathbf{1 2 d}$, in $70 \%$ yield, the same for the two mercurials $\mathbf{1 2 b}$ and $\mathbf{1 3}$, and the same for the two different reactions.

The above syntheses of the mercurials $\mathbf{1 2 b}$ and $\mathbf{1 3}$ may open up an easy way for preparing many other 6-substituted derivatives of 12a (e.g. 12, $\mathrm{X}=\mathrm{F}, \mathrm{Cl}, \mathrm{CN}$ ) by the well-checked by us demercuration procedures explained in Sections 2-4, or otherwise. It would also be possible to prepare readily from 12b and/or $\mathbf{1 3}$ many metallo- and metalloido-organic derivatives of compound 12a, by using known $[23,26,28,34]$ methods applicable for $\mathrm{ArHgX}$ and/or $\mathrm{Ar}_{2} \mathrm{Hg}$ mercurials.

\section{5-Substituted 1,3-Dimethyluracil and 1-Methyluracil Mercurials and Their Demercuration Reactions [6, 8 and 12]}

Uracil [pyrimidine-2,4(1H,3H)-dione] cannot be directly C-mercurated, since it forms at once a sparingly soluble 1:1 mercury complex (N-Hg salt; formula 1 in Section 1) [59] (see however Ref. 60, which will be discussed in Section 8). Contrariwise, 1,3-dimethyluracil (14a, Scheme 7) can be readily directly C-mercurated in its 5-position.

\section{Scheme 7}<smiles>[X]c1cn(C)c(=O)n(C)c1=O</smiles>

14<smiles>Cn1cc([Hg]c2cn(C)c(=O)n(C)c2=O)c(=O)n(C)c1=O</smiles>

15<smiles>[Y]c1cn(C)c(=O)[nH]c1=O</smiles>

16

$$
\begin{aligned}
& \mathrm{X}=\mathrm{H}(\mathbf{a}) ; \mathrm{HgOCOCH}_{3}(\mathbf{b}) ; \mathrm{HgCl}(\mathbf{c}) ; \quad \mathrm{Y}=\mathrm{H}(\mathbf{a}) ; \mathrm{HgOCOCH}_{3}(\mathbf{b}) ; \mathrm{Br}(\mathbf{c}) \\
& \mathrm{I}(\mathbf{d}) ; \mathrm{Br}(\mathbf{e}) ; \mathrm{Cl}(\mathbf{f}) ; \mathrm{F} \mathrm{(g)}
\end{aligned}
$$

We applied routine $[23,24,26,28,34]$ mercurating procedures by reacting 14a either with a boiling aq. $\mathrm{Hg}\left(\mathrm{OCOCH}_{3}\right)_{2}$ solution containing $\mathrm{CH}_{3} \mathrm{CO}_{2} \mathrm{H}$, for 4 hours (which gave pure mercurial 14b in $52 \%$ yield), or with a boiling buffered $\mathrm{C}_{2} \mathrm{H}_{5} \mathrm{OH} / \mathrm{H}_{2} \mathrm{O}$ solution of $\mathrm{HgCl}_{2}$, for 4 hours, which gave pure mercurial 14c in $64 \%$ yield. The same compound $14 \mathbf{c}$ was also obtained in $45 \%$ yield on adding $\mathrm{NaCl}$ to a hot aq. solution of $\mathbf{1 4 b}$. Subsequently, we prepared symmetric pure mercurial 15 by reacting 14b with a hot boiling aq. KI solution, for 0.5 hour, in $89 \%$ yield, after recrystallization from water. 
Subsequently, continuing our previous studies related in Sections 2 - 4, we carried out the following chemical experiments on halo-demercuration of the 1,3-dimethyluracil mercurials $\mathbf{1 4 b}$ and/or 15, viz.

i) on reacting $\mathbf{1 4 b}$ or 15 with hot aq. $\mathrm{KI}_{3}$ solutions, we obtained known pure 5-iodo-1,3-dimethyluracil $(\mathbf{1 4 d})$ in $88 \%$ or $83 \%$ yields, respectively;

ii) on reacting $\mathbf{1 4 b}$ or 15 with hot $\left(80^{\circ} \mathrm{C}\right)$ aq. $\mathrm{KBr}_{3}$ solutions (adjusted in advance to $\mathrm{pH}=7$ ), we obtained known pure 5-bromo-1,3-dimethyluracil (14e) in the same $82 \%$ yield;

iii) on reacting only dry $\mathbf{1 5}$ with a large excess of pure liquid $\mathbf{S}_{\mathbf{2}} \mathbf{C l}_{\mathbf{2}}$, we obtained known pure 5chloro-1,3-dimethyluracil (14f) in 74\% yield;

$i v$ ) on reacting only dry $\mathbf{1 5}$ with a large excess of neat liquefied $\mathbf{S F}_{\mathbf{4}}$ for 48 hours at $-\left(60-70^{\circ} \mathbf{C}\right)$, and following workup explained in Ref. 12, pure compound $\mathbf{1 4 g}$ was produced in $30.3 \%$ yield [12].

So far, there is no easy method of removing N-methyl group(s) from the uracil ring system. Therefore, there is (so far) no easy way of transforming compounds $\mathbf{1 4 d - g}$, into the respective nonmethylated analogues. See however Section 7, where such the demethylation was possible for 5substituted 2,4-dimethoxypyrimidines.

Uracil has two $\mathrm{N}-\mathrm{H}$ groups, which differ chemically and otherwise, e.g. at $25^{\circ} \mathrm{C}$ [61]: $\mathrm{pK}_{\mathrm{a}}(1-\mathrm{N}-\mathrm{H})$ $=9.43 ; \mathrm{pK}_{\mathrm{a}}^{\prime}(3-\mathrm{N}-\mathrm{H})$ ca. 13.2 (estimate). In order to check whether or not the 1-N-H group alone must be blocked to accomplish a successful direct mercuration in position 5, we synthesized 1-methyluracil (16a), and we subsequently carried out its routine mercuration with a boiling, slightly acidified with $\mathrm{CH}_{3} \mathrm{CO}_{2} \mathrm{H}$, aq. $\mathrm{Hg}\left(\mathrm{OCOCH}_{3}\right)_{2}$ solution, for 3.5 hours, which resulted in the formation of mercurial $\mathbf{1 6 b}$ (purified) in 49\% yield; by its bromo-demercuration, similarly to that of $\mathbf{1 4 b}$, we obtained 5 bromo-1-methyluracil (purified) in 78\% yield. In fact, also other 1-N-substituted uracils, e.g. uridine [62] and 2'-deoxyuridine [63] were readily mercurated in their positions 5 with buffered aq. $\mathrm{Hg}\left(\mathrm{OCOCH}_{3}\right)_{2}$ solutions.

\section{5-Substituted 2,4-Dimethoxypyrimidine Mercurials and Their Demercuration Reactions as well as an Indirect Method for Preparing 5-Halogeno-substituted Uracils [6, 9 and 12]}

2,4-Dimethoxypyrimidine (17, Scheme 8) was readily mercurated with a boiling aq. $\mathrm{Hg}\left(\mathrm{OCOCH}_{3}\right)_{2}$ solution acidified with $\mathrm{CH}_{3} \mathrm{CO}_{2} \mathrm{H}$, for 2 hours, and this hot solution containing 18 was applied at once in subsequent reactions (vide infra) [only a small isolated sample of $\mathbf{1 8}$ was recrystallized from ethanol, and its ${ }^{1} \mathrm{H}-\mathrm{NMR}$ spectrum was run for identification purposes].

By adding an aq. $\mathrm{NaCl}$ solution to the aforementioned hot solution containing $\mathbf{1 8}$, the metathesized, insoluble mercurial 20 was precipitated out and collected to give $48 \%$ crude yield (Scheme 8). By adding dropwise a nearly saturated aq. KI solution to the afore-said hot solution containing $\mathbf{1 8}$, and refluxing for 0.5 hour, the symmetrized mercurial 21 (recrystallized from water) was isolated in $\mathbf{7 9 \%}$ yield. 


\section{Scheme 8}

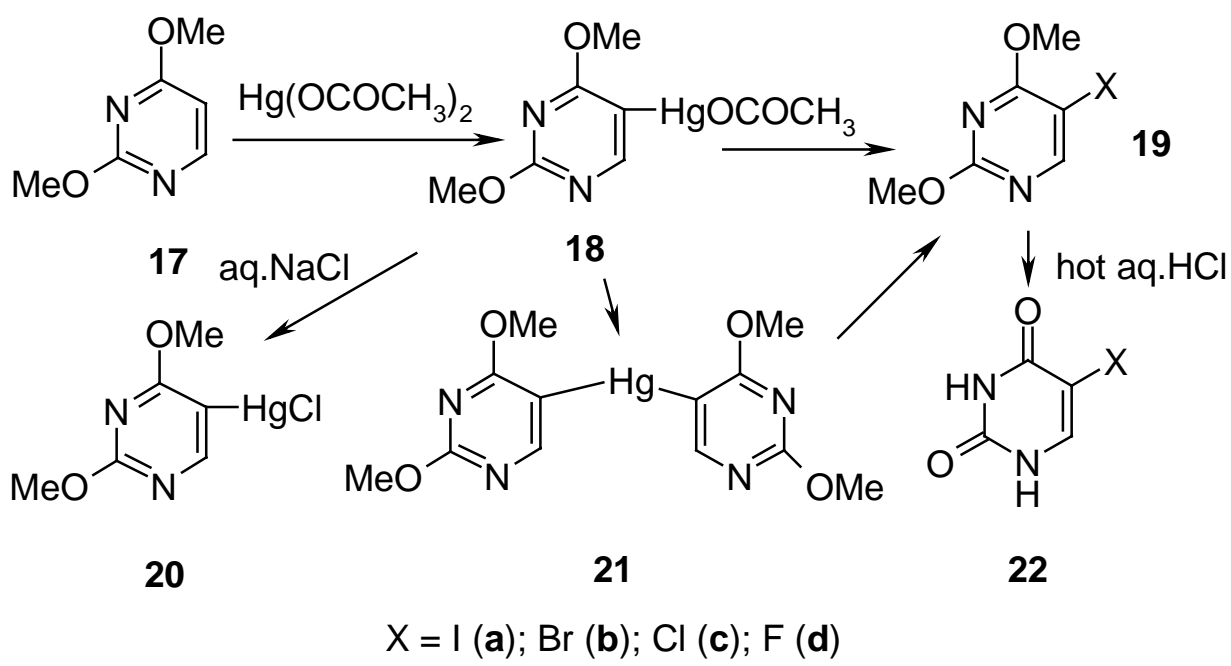

Similarly, an appropriate amount of $\mathrm{I}_{2}$ was added to the boiling aforementioned solution containing 18, which resulted (after cooling) in the isolation of iodo derivative 19a in 58\% yield (purified); alternatively, the same compound 19a (purified) was obtained from solid organomercurial 21 by its iodo-demercuration with a saturated hot $\left(60^{\circ} \mathrm{C}\right)$ aq. $\mathrm{KI}_{3}$ solution, for 45 minutes, which resulted in $52 \%$ yield of 19a. Bromo-demercuration of 18 was attained by adding a neutralized aq. $\mathrm{KBr}_{3}$ solution to the afore-said solution containing 18, and next the reaction was carried out at $60-80^{\circ} \mathrm{C}$ for 45 minutes - isolation of bromo derivative 19b (purified) resulted in 51\% yield; also solid organomercurial 21 was similarly bromo-demercurated to give 19b (purified) in 55\% yield. Solid organomercurial $\mathbf{2 1}$ was chloro-demercurated with excess of freshly redistilled liquid $\mathbf{S}_{\mathbf{2}} \mathbf{C l}_{\mathbf{2}}$ (to avoid the undesirable presence of $\mathrm{SCl}_{2}$; see Section 4 for the explanation). The reaction transcurred for 8 hours at $20^{\circ} \mathrm{C}$, and the reaction mixture was then left overnight - after its two-step workup, pure 5chloro-2,4-dimethoxypyrimidine (19c) was produced in 49\% yield. On reacting symmetric mercurial 21 with a large excess of neat liquefied $\mathbf{S F}_{\mathbf{4}}$ at -(60-70) for 48 hours and the following workup explained in Ref. 12, pure compound 19d was obtained in $32.6 \%$ yield.

5-Halogeno-2,4-dimethoxypyrimidines 19a, 19b, 19c, and 19d, were readily demethylated by adding them to a $10 \%$ aq. hydrochloric acid (used in a large excess), and by evaporating the solutions to dryness on a boiling water bath; the reactions were accompanied by vigorous foaming. The residues were recrystallized to give pure 5-halogeno-substituted uracils 22a, 22b, 22c, and 22d in 69\%, 83\%, $69 \%$ and $81 \%$ [12] yields, respectively. The title method is called indirect, because compound $\mathbf{1 7}$ is prepared from uracil, converted first by $\mathrm{POCl}_{3}$ into 2,4-dichloropyrimidine, which next is reacted upon with $\mathrm{CH}_{3} \mathrm{ONa}$, yielding finally compound 17 [64]. In reverse, also the direct demethylation of 2,4-dimethoxypyrimidine (17) was easily accomplished on heating 17 with hot hydrochloric acid [65]. 
8. 5-Substituted Uracil Mercurials and Their Demercuration Reactions [4, 6, 9, 12 and 14]

In Section 6 we reported that 1-methyluracil (16a) may be readily C-mercurated to give 5(acetoxymercurio)-1-methyluracil (16b) which next was bromo-demercurated to give 5-bromo-1methyluracil (16c). There is (so far) no easy and effective method for removing N-methyl group(s) in the uracil ring system, hence it is not possible to obtain e.g. 5-bromouracil (26b) from compound 16c. However, it is known [66] that 1-acetyluracil (23) is readily deacetylated even by cold water to form the initial uracil. We made numerous attempts to mercurate $\mathbf{2 3}$ in various anhydrous solvents with the less reactive mercurating agents, viz. $\mathrm{HgCl}_{2}$ or $\mathrm{Hg}\left(\mathrm{OCOCH}_{3}\right)_{2}$ (Scheme 9). On prolonged heating only the sparingly soluble N-Hg salt of uracil (formula 1 in Section 1) was precipitated out in excellent yields, probably with a negligible $\mathrm{C}$-mercuration in position 5.

Finally, we effectively $\mathrm{C}_{5}$-mercurated $\mathbf{2 3}$ in boiling anhydrous acetonitrile, for 10 hours, but only with the strongly electrophilic $\left.\mathbf{H g}(\mathbf{O C O C F})_{3}\right)_{2}$. We did not isolate the intermediate mercurial 24, but rather its yellowish, clear hot solutions were applied as such in the following reactions (vide infra); when the same mercuration was carried out, quite similarly, in $\mathrm{CD}_{3} \mathrm{CN}$, then the presence of the soluble mercurial 24 was confirmed by ${ }^{1} \mathrm{H}-\mathrm{NMR}$ spectroscopy.

\section{Scheme 9}

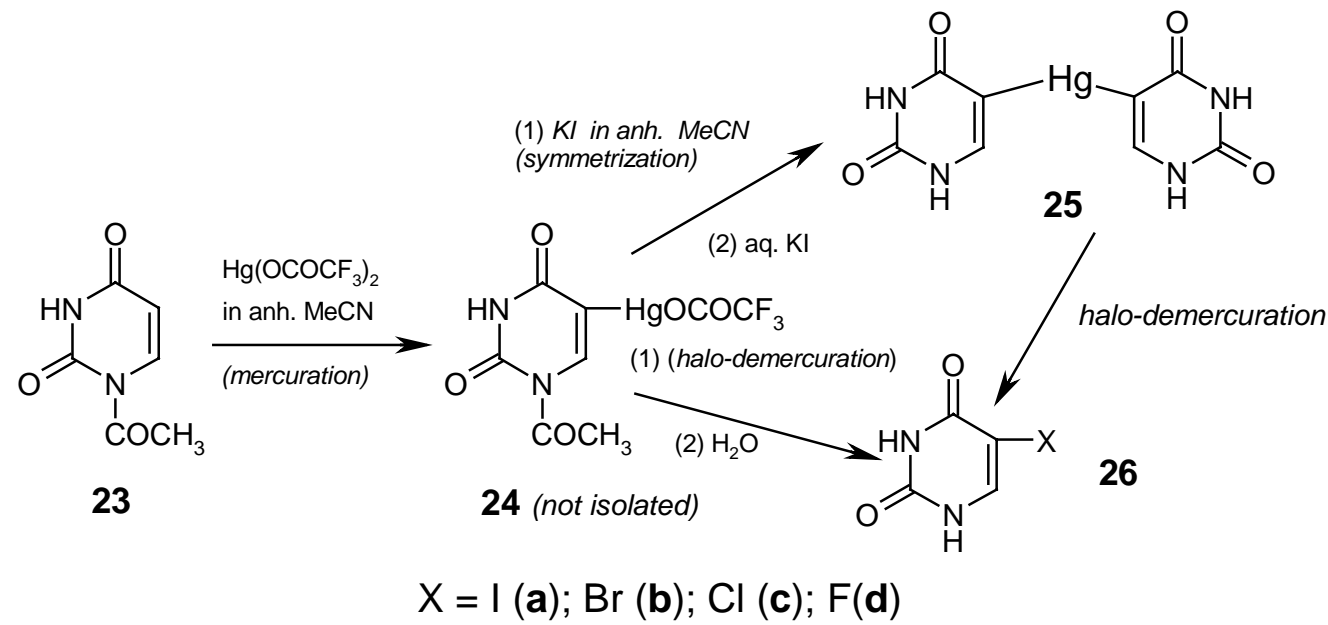

If we prolonged for more than ten hours the above mercuration reaction, a white solid was precipitated out in still increasing amounts, and it represented the $\mathrm{N}-\mathrm{Hg}$ salt $\mathbf{1}$, but substituted with the $\mathrm{HgOCOCF}_{3}$ group in its position 5 (which was confirmed chemically, spectrally, and in part, analytically). The desirable 5,5'-mercuriobis(uracil) (25) was obtained in 50\% crude yield by adding excess KI dissolved in $d r y$ acetonitrile to the afore-said yellowish solution of $\mathbf{2 4}$. This mixture was refluxed for 4 hours, cooled, and filtered. The collected white precipitate was heated for 30 minutes at $60^{\circ} \mathrm{C}$ with a saturated aq. KI solution [which also split off the 1-N-acetyl groups] and after cooling, the collected white precipitate was washed well with boiling water, dried, and analyzed. Its structure was confirmed by the routine iodo-demercuration reaction with a hot aq. $\mathrm{KI}_{3}$ solution to give known compound 26a (purified) in 93\% yield; see Ref. 4 for details. Alternatively, the same iodo- 
demercuration reaction was carried out but with using the aforementioned yellowish boiling solution of 24, which was treated at first with diiodine and next the collected white precipitate was heated for 30 minutes, at $60^{\circ} \mathrm{C}$, with an aq. KI solution to give finally $\mathbf{2 6 a}$ (purified) in $60 \%$ yield.

The respective routine bromo-demercuration reactions with hot aq. $\mathrm{KBr}_{3}$ solutions (prior adjusted to $\mathrm{pH}=7$ ) of either solid $\mathbf{2 5}$ or $\mathbf{2 4}$ (in its $\mathrm{CH}_{3} \mathrm{CN}$ solution) were reported elsewhere [9], and gave known purified 5-bromouracil (26b) in $84 \%$ and $77 \%$ yields, respectively. The above results confirm a somewhat lesser reactivity of unsymmetric mercurial $\mathbf{2 4}$ as compared with symmetric mercurial 25.

The chloro-demercuration of symmetric mercurial 25 was reported in our paper [4]. Solid 25 was slowly added to the freshly-redistilled $\mathbf{S}_{\mathbf{2}} \mathbf{C l}_{\mathbf{2}}$ (used in excess), and this was left overnight at room temperature. The collected precipitate was washed with dry $\mathrm{CH}_{3} \mathrm{CN}$, recrystallized from ethanol to give known purified 5-chlorouracil (26c) in 65\% yield.

The novel fluoro-demercuration procedure, presented in Ref. 12, gave 5-fluorouracil (26d) in $27.1 \%$ yield, by reacting symmetric mercurial 25 with a large excess of neat liquid $\mathbf{S F}_{\mathbf{4}}$ for 48 hours at ca $-60^{\circ} \mathrm{C}$, and the subsequent workup; see Section 7 for another method of preparing compound $\mathbf{2 6 d}$.

Note. The electron-donating groups, viz. the methyl or methoxy groups in caffeine, 2,3-diphenyl5-methoxybenzo[b]furan, 1,3-dimethyluracil and 1-methyluracil, and 2,4-dimethoxypyrimidine do increase more or less an electron density in the substituted parent heterocyclic systems, facilitating thus their direct mercuration even with less electrophilic mercuric salts, viz. mercuric acetate, sometimes also with $\mathrm{HgCl}_{2}$ in its buffered aq. solutions. In contrast, any electron-withdrawing $\mathrm{N}$-acyl groups (e.g. the acetyl, trichloroacetyl or trifluoroacetyl groups), which were introduced by us into the uracil, theophilline or theobromine parent ring systems, render considerably more difficult their direct mercurations with $\mathrm{Hg}\left(\mathrm{OCOCH}_{3}\right)_{2}$, and completely eliminate the use of $\mathrm{HgCl}_{2}$. It is why we had to use the strongly electrophilic $\mathbf{H g}\left(\mathrm{OCOCF}_{3}\right)_{2}$, usually prior prepared in situ, to effectively mercurate Nacylated uracil (Section 8), theophilline (Section 9), and theobromine (Section 10) in anhydrous solvents to obtain possibly highest yields of the desired C-substituted unsymmetric mercurials.

Visser et al. [60] have succeded to synthesize microquantities of radioactive 5-X-uracils ( $\mathrm{X}={ }^{211} \mathrm{At}$ or ${ }^{131} \mathrm{I}$ ) by reacting $45 \mu \mathrm{mol}$ of uracil, dissolved in $1 \mathrm{ml}$ of $0.2 \mathrm{M}$ aq. $\mathrm{H}_{2} \mathrm{SO}_{4}$, with $\mathrm{HgSO}_{4}(40 \mu \mathrm{mol})$, for 3 hours at room temperature, followed with $\mathrm{NaCl}(90 \mu \mathrm{mol})$. Without isolating the intermediate 5 (chloromercurio)uracil, they added subsequently 0.9 equivalent of ${ }^{211} \mathrm{At} / \mathrm{I}_{2}$ or ${ }^{131} \mathrm{I} / \mathrm{I}_{2}$, which resulted in very good radiochemical yields of final radioactive products. Similar approaches were used, with varying reaction times and temperatures, e.g. for imidazole, thyrosine, phenylalanine, etc. We scaled up [14] the aforementioned procedure a thousandfold (i.e. to the millimolar scale) as to directly $\mathrm{C}_{5^{-}}$ mercurate uracil as well as, for the sake of comparison, 2-thiouracil and theobromine. Only uracil gave 5-(chloromercurio)uracil in $85 \%$ crude yield; its following routine iodo-demercuration with a hot $\left(80^{\circ} \mathrm{C}\right)$ aq. $\mathrm{KI}_{3}$ solution led to 5-iodouracil in ca $61 \%$ crude yield. All our attempts to symmetrize 5-(chloromercurio)uracil by means of hot aq. KI, $\mathrm{Na}_{2} \mathrm{~S}_{2} \mathrm{O}_{3}$ or $\mathrm{KSCN}$ solutions as well as by a methanolic solution of hydrazine were not successful. Therefore, the symmetric mercurial 25 should be prepared in the way explained above. Theobromine reacted as above [60] but in the millimolar scale, furnished 1-N-(chloromercurio)theobromine in ca 77\% crude yield, which being iodo-demercurated gave the initial theobromine in ca $72 \%$ yield, with no detectable amount of the expected 
8-iodotheobromine; see also Section 12. Similarly, 2-thiouracil reacted as above [60] but on a millimolar scale, forming nearly quantitatively an insoluble crude mercurial, which after its demercuration with an aq. KI solution, yielded solely the initial 2-thiouracil with no detectable amount of any C-mercurated product. We concluded [14] the above experiments as follows: "the direct mercuration procedure offered in Ref. 60 should always be tried in the future, since it is relatively simple and less hazardous than the other ones (cf. Section 11), though it is less general than it has been expected and wanted".

\section{8-Substituted Theophylline Mercurials and Their Demercuration Reactions [3, 4]}

When theophylline as well as theobromine and uracil, all having acidic N-H groups, are reacted with $\mathrm{Hg}$ (II) salts, then their sparingly soluble $\mathrm{N}-\mathrm{Hg}$ salts (see formulae $\mathbf{1}-\mathbf{3}$ in Section 1) are immediately precipitated out from the mercurating solutions $[63,66]$, and their effective Cmercuration cannot be performed; see Section 8, where this topic is discussed. N-Acetyl derivatives of theophylline and theobromine [67], are easily hydrolyzable by the action of water, likewise as does 1-acetyluracil (Section 8).

\section{Scheme 10}

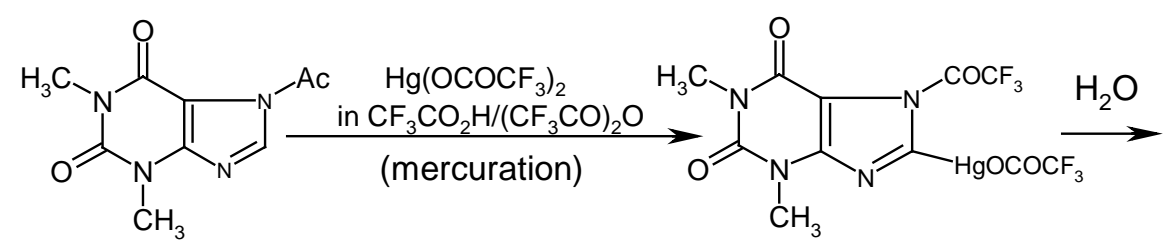

27

28

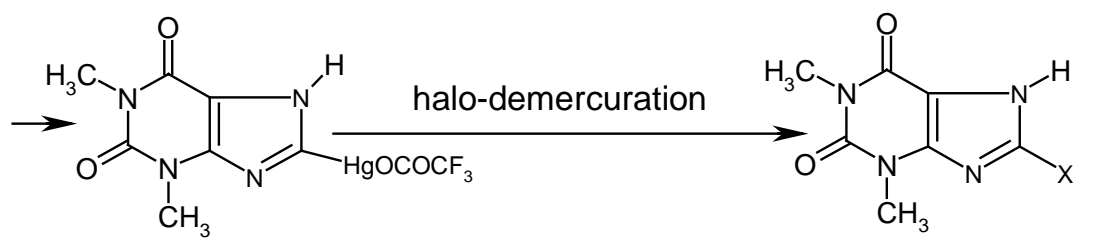

29

30

$$
\begin{aligned}
& \mathrm{Ac}=\mathrm{COCH}_{3}(\mathbf{a}) ; \\
& \mathrm{COCF}_{3}(\mathbf{b}) ; \operatorname{COCCl}_{3}(\mathbf{c})
\end{aligned} \quad \mathrm{X}=\mathrm{I}(\mathbf{a}) ; \mathrm{Br}(\mathbf{b}) ; \mathrm{Cl}(\mathbf{c})
$$

We made many attempts to mercurate 7-acetyltheophylline (27a) in various anhydrous media, e.g. in $\mathrm{CH}_{3} \mathrm{CO}_{2} \mathrm{H} /\left(\mathrm{CH}_{3} \mathrm{CO}\right)_{2} \mathrm{O}$ mixtures, with less reactive mercurating agents, viz. $\mathrm{HgCl}_{2}$ or $\mathrm{Hg}\left(\mathrm{OCOCH}_{3}\right)_{2}$, but all our experiments were unsuccessful for the same reasons as those explained for 1 -acetyluracil (Section 8). We succeeded in C-mercurating the theophylline system in its 8-position (which is somewhat more reactive than the same position in theobromine and caffeine), but only by using the strongly electrophilic $\left.\mathbf{H g}(\mathbf{O C O C F})_{3}\right)_{2}$ dissolved in boiling anhydrous mixtures made of $\mathrm{CF}_{3} \mathrm{CO}_{2} \mathrm{H}$ and $\left(\mathrm{CF}_{3} \mathrm{CO}\right)_{2} \mathrm{O}$. The reaction was complete after 10 hours, the resulting reaction mixture was concentrated under dimished pressure, water was added to the viscous residue, and a white 
precipitate collected was recrystallized from water to give 8-(trifluoracetoxymercurio)theophylline (29) in 53\% yield. We also simplified the above procedure as follows. Theophylline was refluxed with $\left(\mathrm{CF}_{3} \mathrm{CO}\right)_{2} \mathrm{O}$ for 2 hours [thus, 7-(trifluoroacetyl)theophylline $(\mathbf{2 7 b})$ was produced there in situ], then a solution of $\mathrm{Hg}\left(\mathrm{OCOCF}_{3}\right)_{2}$ in $\mathrm{CF}_{3} \mathrm{CO}_{2} \mathrm{H} /\left(\mathrm{CF}_{3} \mathrm{CO}\right)_{2} \mathrm{O}$ was added, and the same mercuration reaction was carried out under a reflux condenser for 10 hours; the subsequent workup was the same as previously described to afford mercurial 29 in $64 \%$ yield. This yield was later increased to $70 \%$, when 7-(trichloroacetyl)theophylline (27c) was used as the starting substrate (Ref. 4; see footnote on p. 386).

Next, we carried out the routine iodo- and bromo-demercuration reactions with mercurial 29 in hot aq. $\mathrm{KI}_{3}$ or $\mathrm{KBr}_{3}$ solutions (previously adjusted to $\mathrm{pH}=7$ ), at $80^{\circ} \mathrm{C}$ for 30 minutes, which gave the purified compounds 30a and 30b in 95\% and 96\% yields, respectively. However, our attempts to prepare 8-chlorotheophilline (30c) from dry unsymmetric mercurial $\mathbf{2 9}$, using pure liquid $\mathbf{S}_{\mathbf{2}} \mathbf{C l}_{\mathbf{2}}$ or $\mathbf{S C l}_{\mathbf{2}}$ as the chloro-demercuration agents, were unsuccessful.

\section{8-Substituted Theobromine Mercurials and Their Demercuration Reactions [3, 4 and 13]}

Since all our experiments on the C-mercuration of theobromine and theophylline, published in [3], were performed in parallell and were very close ones to the others, hence there is no need to relate here all our unsuccessful preliminary experiments aimed at the preparation of the desired theobromine mercurial(s). As previously, we succeeded in the mercuration of 1-acetyltheobromine (31a) only with $\mathbf{H g}\left(\mathbf{O C O C F}_{3}\right)_{2}$ in boiling anhydrous $\mathrm{CF}_{3} \mathrm{CO}_{2} \mathrm{H} /\left(\mathrm{CF}_{3} \mathrm{CO}\right)_{2} \mathrm{O}$ mixtures, for 10 hours. The following workup was practically the same as that for preparing mercurial 29, which gave 8-(trifluoroacetoxymercurio)theobromine (32a) in 56\% yield (Scheme 11). Later (Ref. 4; see footnote on p. 386), we increased this yield to $70 \%$ by using 1 -(trichloroacetyl)theobromine (31c) as the starting substrate.

\section{Scheme 11}<smiles>Cn1c(=O)c2c(ncn2C)n(C)c1=O</smiles><smiles>[X]c1nc2c(=O)n(C)[nH]c(=O)c2n1C</smiles><smiles>Cn1c(S)nc2c1c(=O)[nH]c(=O)n2C</smiles>

Analysis: For $\mathrm{C}_{14} \mathrm{H}_{14} \mathrm{HgN}_{8} \mathrm{O}_{4}$ Calc. $35.9 \% \mathrm{Hg}$, Found: $35.8 \% \mathrm{Hg}(\mathrm{II})$

$\mathrm{Ac}=\mathrm{COCH}_{3}(\mathbf{a}) ; \mathrm{COCF}_{3}(\mathbf{b}) ; \mathrm{COCCl}_{3}(\mathbf{c})$

$\mathrm{X}=\mathrm{HgOCOCF}_{3}(\mathbf{a}) ; \mathrm{I}(\mathbf{b}) ; \mathrm{Br}(\mathbf{c})$; 
As previously, the solid unsymmetric mercurial 32a was next iodo- and bromo-demercurated with hot $\left(80^{\circ} \mathrm{C}\right)$ aq. $\mathrm{KI}_{3}$ or aq. $\mathrm{KBr}_{3}(\mathrm{pH}=7)$ solutions, under nearly the same reaction conditions as those related in Section 9, which resulted in the purified 8-iodo- (32b) and 8-bromo-theobromine (32c) obtained in $95 \%$ and $92 \%$ yields, respectively. Our attempted chloro-demercuration experiments with mercurial 32a upon reaction with neat $\mathbf{S}_{\mathbf{2}} \mathbf{C l}_{\mathbf{2}}$ or $\mathbf{S} \mathbf{S C l}_{\mathbf{2}}$ were quite unsuccessful as well.

Later [13], we prepared pure 8,8'-mercuriobis(theobromine) (33) in $88 \%$ yield, though only from 1,8-bis(acetoxydimercurio)theobromine (34). Using the routine iodo- and bromo-demercuration methods with the symmetric mercurial 33, we obtained the purified either 8-iodo- (32b) or 8-bromotheobromine (32c) in 97\% and 92\% yields, respectively. However, the contents of our paper [13] will be discussed more extensively in Section 11 below.

\section{Preparation of 1,8-bis(Acetoxydimercurio)theobromine and Its Reactions [13]}

Australian chemists [52] have prepared numerous fully mercurated (permercurated) arenes by the reaction of an excess of molten $\left.\mathbf{H g}(\mathbf{O C O C F})_{3}\right)_{2}$ with suitable arenes at ca $180-245^{\circ} \mathrm{C}$; the reaction temperature used depended on the reactivity of a given starting arene. The crude (i.e. not analyzed) permercurated arenes were subsequently halo-demercurated to give the corresponding perhalogenated arenes. Therefore, we expected that the same melting chemical procedure would be suitable for the direct permercuration of several fairly stable, N-H acidic, lactamic heterocycles, e.g. theobromine, theophylline, xanthine, hypoxanthine, uracil, etc. For our preliminary study we chose theobromine, whose mercurials are discussed in Section 10.

\section{Scheme 12}

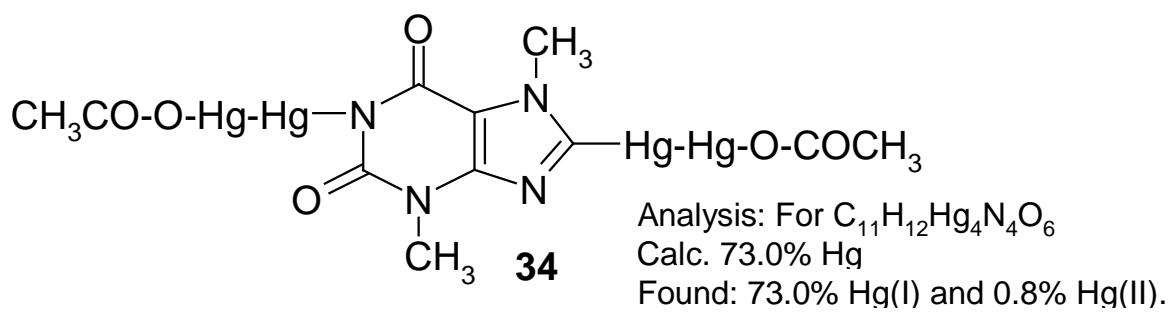

In order to accomplish the said melting chemical procedure, we intimately mixed pure theobromine with an excess of molten $\left.\mathbf{H g}(\mathbf{O C O C F})_{3}\right)_{2}$ (prepared in situ). A vigorous reaction was observed with the evolution of gaseous, strongly toxic products as well as tiny droplets of metallic mercury. This is why, in our opinion, the organic derivatives of mercury $(I)$ would readily be formed in the hot reaction mixture.

Note. We submitted in our paper [13] the following assumption (see footnote on p. 30): Mercury in statu nascendi $\left(\mathrm{Hg}^{*}\right)$, probably formed during the thermal decomposition of $\mathrm{Hg}\left(\mathrm{OCOCF}_{3}\right)_{2}$, would, at a guess, react readily with intermediates of mercury(II), forming the resulting compounds of mercury(I), viz. 


\section{Scheme 13}

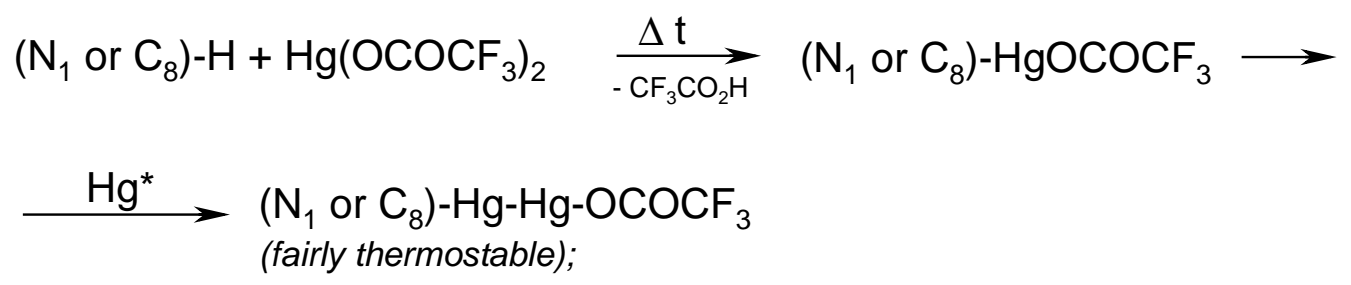

excess $\mathrm{Hg}^{*} \rightarrow$ metallic mercury

The main problem was how to properly control the reaction temperature, since the aforementioned reaction mixture thickened continuosly, until it had solidified. In hindsight, it would probably be desirable in the future to identify some suitable inert solvents, e.g. some highly boiling hydrocarbons or perfluorinated hydrocarbons, in order to better control the reaction. For the time being, we obtained some crude melt, evidently containing tiny droplets of metallic mercury as well as some highly mercurated products, most likely 1,8-bis(trifluoroacetoxydimercurio)theobromine. The latter tentative opinion was further indirectly supported by the subsequent reaction. On boiling the powdered crude melt with glacial acetic acid - where the following metathesis would take place: $-\mathrm{Hg}-\mathrm{Hg}-\mathrm{OCOCF}_{3}+$ excess $\mathrm{CH}_{3} \mathrm{COOH} \rightarrow-\mathrm{Hg}-\mathrm{Hg}-\mathrm{OCOCH}_{3}+\mathrm{CF}_{3} \mathrm{CO}_{2} \mathrm{H}-$ a considerably purer yellow product was obtained (after the concentration of the $\mathrm{CH}_{3} \mathrm{CO}_{2} \mathrm{H}$ extract under reduced pressure) in $28 \%$ yield calculated with respect to the starting theobromine. Its analysis is given in the Scheme above. Its ${ }^{1} \mathrm{H}-\mathrm{NMR}$ spectrum (in $\mathrm{CF}_{3} \mathrm{COOD}$ ) shows the absence of any $8-\mathrm{H}$ low-field proton signal at ca. 8.5 ppm, and the presence of two $\mathrm{N}-\mathrm{CH}_{3}$ three-proton signals (at 3.38 and $4.08 \mathrm{ppm}$ ) characteristic of theobromine [3]. At ca $1.8 \mathrm{ppm}$ there is, however, an additional and intense six-proton singlet derived from two, apparently spectrally equivalent, $\mathrm{CH}_{3} \mathrm{COO}$ groups. Thus, it may be guessed that the two assumed $-\mathrm{Hg}-\mathrm{Hg}-\mathrm{OCOCH}_{3}$ groups are substituted in mercurial $\mathbf{3 4}$ in its 1 and 8 positions. The lack of any $1-\mathrm{N} H$ proton signal is insignificant, since it might have been due to a quick isotopic exchange with the deuterated solvent. Hence, the said substitution in position 1 is better explained by the full absence of any characteristic N-H absorption band over the $3070-3150 \mathrm{~cm}^{-1}$ IR range which, in contrast, is found at $3120 \mathrm{~cm}^{-1}$ in the comparative IR spectrum of theobromine taken also in Nujol.

This considerably purified product $\mathbf{3 4}$ was used as such in the following reactions without further purification. Compound $\mathbf{3 4}$ was readily iodo- and bromo-demercurated with either a boiling $\mathrm{I}_{2}$ solution in dry $\mathrm{CH}_{3} \mathrm{CN}$, for 1.5 hours, or by an aq. $\mathrm{KBr}_{3}$ solution, at $80^{\circ} \mathrm{C}$ for one hour, to give finally either 8-iodotheobromine (32b) (purified) in 97\% yield, or 8-bromotheobromine (32c) (purified) in 92\% yield; in the course of both demercuration procedures, the $\left(\mathrm{N}_{1}\right)-\mathrm{Hg}-\mathrm{Hg}-\mathrm{OCOCH}_{3}$ groups are exchanged in full by the hydrogen atoms (proto-demercuration), whereas those attached to the $\mathrm{C}_{8}$ atom of 34 are replaced by the respective halogen atoms (halo-demercuration). The same difference was observed in the course of our attempted symmetrization of compound $\mathbf{3 4}$ by a hot ethanolic solution of 
hydrazine (the other symmetrizing agents tried were either ineffective or gave worse results). Only the $\mathrm{C}_{8}$-substituted $-\mathrm{Hg}$ - $\mathrm{Hg}-\mathrm{OCOCH}_{3}$ groups were all engaged in the formation of $\mathbf{- H g}$ - bridging present in the formed 8,8'-mercuriobis(theobromine) (33), which was obtained, after its purification, in $88 \%$ yield [its structure was confirmed analytically, spectrally as well as by its subsequent iodo- and bromo-demercuration reactions; see Section 10], whereas those groups substituted in 1-N position were readily split off in favor of the hydrogen atom. All these reactions are new in the field of organic derivatives of mercury $(I)$ - to the best of our knowledge (Note: Organic C-derivatives of mercury $(I)$ so far are rare and generally regarded as unstable. For example, controlled electrolysis of 1,6dibromohexane with a mercury cathode gives the dimer $\left.\left[\mathrm{Me}\left(\mathrm{CH}_{2}\right)_{5} \mathrm{Hg}\right]_{2}[68]\right)$.

It is impossible not to mention that the permercurated arenes prepared by the Australian chemists [52] had been neither purified nor analyzed, but they were immediately used as such in the subsequent halo-demercuration reactions, resulting in numerous, purified and analyzed, perhalogenated arenes. Nobody knows whether the said intermediate permercurated arenes were, in fact, the derivatives of mercury(II), mercury(I) or, possibly, were composite mixtures of both; this should be elucidated in future.

\section{Further Studies on Some Heteroaromatic Mercurials [14]}

Using various known methods of direct $\boldsymbol{C}$-mercuration we attempted to mercurate uracil, thiouracil (35a), S-ethyl-2-thiouracil (35b), theobromine (36a) and 6-O-ethyltheobromine (37). Only uracil was effectively $\mathrm{C}_{5}$-mercurated giving the crude 5-(chloromercurio)uracil (Section 8) in ca $85 \%$ crude yield, whereas the rest formed (in good yields) either S-Hg bonds (compounds 35a and 35b) or $\mathrm{N}-\mathrm{Hg}$ bonds (compounds 36a and 37); in the latter its 6-O-ethyl groups were completely split off under the reaction conditions. All the newly obtained crude mercurials were next iodo-demercurated by the routine methods [23-25, 34, 42]. This furnished from S-ethyl-2-thiouracil mercurial the corresponding C-iodinated product, i.e. S-ethyl-5-iodo-2-thiouracil (35c) in ca 64\% crude yield.

\section{Scheme 14}<smiles>[R5]Sc1ncc([Y])c(O)n1</smiles>

35<smiles>[X]n1c(=O)c2c(ncn2C)n(C)c1=O</smiles>

36<smiles>COc1nc(=O)n(C)c2ncn(C)c12</smiles>

37

$\mathrm{R}=\mathrm{H}, \mathrm{Y}=\mathrm{H}(\mathbf{a})$;

$\mathrm{X}=\mathrm{H}(\mathbf{a})$;

$\mathrm{R}=\mathrm{C}_{2} \mathrm{H}_{5}, \mathrm{Y}=\mathrm{H}(\mathbf{b})$;

$\mathrm{R}=\mathrm{C}_{2} \mathrm{H}_{5}, \mathrm{Y}=\mathrm{I}(\mathbf{c})$;

$\mathrm{X}=\mathrm{HgOCOCH}_{3}(\mathbf{b})$;

$\mathrm{X}=\mathrm{HgCl}(\mathbf{c})$

The other mercurials were mostly proto-demercurated, though with some noticeable exceptions which are discussed below. The main purpose of our work [14] was to detect whether the 
aforementioned crude mercurials do contain (or not) any detectable amounts of C-mercurated admixtures, which would then have been transformed into recognizable $C$-iodinated derivatives formed in the subsequent iodo-demercuration reactions.

It has been shown in Section 7 that 2,4-dimethoxypyrimidine (17) was effectively $\mathrm{C}_{5}$-mercurated on boiling with an aq. $\mathrm{Hg}\left(\mathrm{OCOCH}_{3}\right)_{2}$ solution acidified with $\mathrm{CH}_{3} \mathrm{CO}_{2} \mathrm{H}$, for 2 hours. Hence, we did expect that compound $\mathbf{3 7}$ would behave similarly to give a true mercurial C-substituted in position 8 . Thus, compound 37 was refluxed for 55 hours with a $\mathrm{Hg}\left(\mathrm{OCOCH}_{3}\right)_{2}$ solution in boiling glacial acetic acid (the reaction was monitored with TLC). Quite unexpectedly, we obtained a new mercurial 36b, i.e. 1-(acetoxymercurio)theobromine, in $83 \%$ yield, whose structure was confirmed by chemical tests and its IR and ${ }^{1} \mathrm{H}-\mathrm{NMR}$ spectra; no ${ }^{1} \mathrm{H}-\mathrm{NMR}$ spectral evidence was found for any $\mathrm{C}_{8}$-mercuration. The 6-O-ethyl groups in compound $\mathbf{3 7}$ were completely split off under the reaction conditions, momentarily forming the parent tautomeric theobromine (36a), which immediately reacted with $\mathrm{Hg}\left(\mathrm{OCOCH}_{3}\right)_{2}$ to give the new mercurial $\mathbf{3 6 b}$.

Our assumption was supported as follows: when compound $\mathbf{3 7}$ was refluxed for 48 hours with neat $\mathrm{CH}_{3} \mathrm{CO}_{2} \mathrm{H}$; after cooling, we isolated theobromine (36a) in $83 \%$ yield, which was proven chemically and spectroscopically. We also obtained another new mercurial 36c, i.e. 1-(chloromercurio)theobromine in ca $77 \%$ crude yield (Section 8). The two crude mercurials $36 \mathbf{b}$ and $\mathbf{3 6} \mathbf{c}$ were refluxed for 2 hours with excess diiodine dissolved in dry $\mathrm{CH}_{3} \mathrm{CN}$; after workup this furnished theobromine (36a) in $76 \%$ and $72 \%$ yields, respectively. No detectable amounts of known 8 -iodotheobromine which would have supported the sought $\mathrm{C}_{8}$-mercuration - were found in the both reaction mixtures which furnished only theobromine.

It should be added that, so far, only one theobromine mercurial with a $2: 1 \mathrm{Hg}$ ratio has been reported [69]; its structure is shown in Section 1. In the same paper [69] other $\mathrm{N}-\mathrm{Hg}$ mercurials prepared from theophylline, hypoxanthine, xanthine, guanine and uracil (the latter is a 1:1 Hg complex as shown in Section 1) were also reported.

The new S-ethylthiouracil mercurial (supposedly a 1:1 Hg complex) was synthesized as follows: compound 35b was dissolved in $\mathrm{CH}_{3} \mathrm{OH}$ acidified with two drops of added conc. aq. $\mathrm{HClO}_{4}$. Then a solution of $\mathrm{Hg}\left(\mathrm{OCOCH}_{3}\right)_{2}$ in methanol was added to the former solution, the mixture was refluxed for 8 hours, and then left overnight. The collected white precipitate was practically insoluble in common solvents, and was obtained in ca $42 \%$ crude yield. When this novel crude mercurial was boiled with a conc. aq. KI solution until the combined solution was clear and slightly yellowish, then after cooling we isolated the recovered compound $\mathbf{3 5 b}$ in $99 \%$ yield. But the same crude mercurial upon refluxing with an aq. $\mathrm{KI}_{3}$ solution for $30-40$ minutes, unexpectedly gave (after cooling) the iodo derivative 35c in ca $64 \%$ crude yield; it was recrystallized from ethanol and 2-propanol yielding pure 35c.

\section{Final Results of Our Halo- and Cyano-demercuration Reactions [1-15]}

\subsection{Aromatic Iodides from Aromatic Organomercurials}

It is known [23, 26, 28, 34, 42] that aromatic iodides and bromides may be obtained from both symmetric and unsymmetric aromatic organomercurials, by reacting them with either hot aq. $\mathrm{KI}_{3}$ and 
$\mathrm{KBr}_{3}$ neutralized solutions or with hot solutions of diiodine and dibromine in acetonitrile, DMF, etc. We have repeatedly applied these "classic" iodo-demercuration and bromo-demercuration reactions to better elucidate the chemical structures of organomercurials prepared by us in various ways. Thus, we synthesized (the yields are given in brackets) the following aromatic iodides and bromides, viz.

i) 8-iodocaffeine (95\%) from 8-(acetoxymercurio)caffeine and 8,8'-mercuriobis(caffeine) [1, 2];

ii) 8-iodotheophylline (95\%) from 8-(trifluoroacetoxymercurio)theophylline, and 8-iodotheobromine (95\%) from 8-(trifluoroacetoxymercurio)theobromine [3];

iii) 5-iodouracil (60 or 93\%, resp.) from either 1-acetyl-5-(trifluoroacetoxymercurio)uracil or 5,5'-mercuriobis(uracil) [4];

iv) 2-iodofuran (60\%) from 2,2'-difurylmercury, and 2-iodothiophene (65\%) from 2,2'-dithienylmercury [5];

v) 5-iodo-1,3-dimethyluracil (87.5 or $82.5 \%$, resp.) from either 5-(acetoxymercurio)-1,3-dimethyluracil or 5,5'-mercuriobis(1,3-dimethyluracil) [8];

vi) 5-iodo-2,4-dimethoxypyrimidine (58 or 52\%, resp.) from either 5-(acetoxymercurio)-2,4dimethoxypyrimidine or 5,5'-mercuriobis(2,4-dimethoxypyrimidine); the acid hydrolysis of pure 5-iodo-2,4-dimethoxypyrimidine afforded 5-iodouracil (69\%) [9];

vii) 6-iodo-2,3-diphenyl-5-methoxybenzo[b]furan (70\%) from both 6-(acetoxymercurio)-2,3diphenyl-5-methoxybenzo[b]furan and 6,6'-mercuriobis(2,3-diphenyl-5-methoxybenzo[b]furan) [10];

viii) iodobenzene (59\%) from (chloromercurio)benzene, and 8-iodocaffeine (65\%) from 8-(chloromercurio)caffeine [11];

ix) 8-iodotheobromine (97\%) from 1,8-bis(acetoxydimercurio)theobromine; the latter compound was the first stable organic derivative of mercury(I) [13]

x) 5-iodouracil (61\% crude yield) from 5-(chloromercurio)uracil, and 2-ethylthio-4-hydroxy-5iodopyrimidine (64\% crude yield) from crude 2-ethylthio-4-hydroxypyrimidine mercurial [14].

Note. We also applied twice another iodo-demercuration method, by reacting two symmetric organomercurials with hot either aqueous [1, 2] or ethanolic [7] solutions of cyanogen iodide, ICN. In this way we synthesized:

xi) 8-iodocaffeine (90\%) from 8,8'-mercuriobis(caffeine) [1, 2], and

xii) iodobenzene (72\%) from diphenylmercury [7].

\subsection{Aromatic Bromides from Aromatic Organomercurials}

i) 8-bromocaffeine ( $83 \%$ or $85 \%$, resp.) from either 8 -(acetoxymercurio)caffeine or $8,8^{\prime}$-mercuriobis(caffeine) [1,2];

ii) 8-bromotheophylline (96\%) from 8-(trifluoroacetoxymercurio)theophylline [3];

iii) 8-bromotheobromine (96\%) from 8-(trifluoroacetoxymercurio)theobromine [3, 13];

iv) 5-bromo-1,3-dimethyluracil ( $82 \%$ or $84,5 \%$, resp.) from either 5-(acetoxymercurio)-1,3dimethyluracil or 5,5'-mercuriobis(1,3-dimethyluracil) [8]; 
v) 5-bromo-2,4-dimethoxypyrimidine (51\% or 55\%, resp.) from either 5-(acetoxymercurio)-2,4dimethoxypyrimidine or 5,5'-mercuriobis(2,4-dimethoxypyrimidine); the acid hydrolysis of pure 5-bromo-2,4-dimethoxypyrimidine afforded 5-bromouracil (83\%) [9];

vi) 5-bromouracil (77\% or $84 \%$, resp.) from either 5-(trifluoroacetoxymercurio)uracil or 5,5'-mercuriobis(uracil) [9];

vii) 6-bromo-2,3-diphenyl-5-methoxybenzo[b]furan (70\%) from both 6-(acetoxymercurio)-2,3diphenyl-5-methoxybenzo[b]furan or 6,6'-mercuriobis(2,3-diphenyl-5-methoxybenzo[b]furan) [10].

viii) 8-bromotheobromine (92\%) from both 8,8`-mercuriobis(theobromine) or 1,8-bis(acetoxydimercurio)theobromine [13].

Note. We also applied twice our novel bromo-demercuration method, with applying a labile complex (or adduct) of an unknown composition, $(\mathbf{B r C N} \cdot \mathbf{K B r})_{\mathbf{x}}$, suspended either in hot water $[1,2]$ or dissolved in boilling ethanol [7]. In this way we obtained:

ix) 8-bromocaffeine (85\%) from both 8-(acetoxymercurio)caffeine or 8,8`-mercuriobis(caffeine) $[1,2]$

x) bromobenzene (79\%) from diphenylmercury [7].

\subsection{Aromatic Chlorides from Aromatic Organomercurials}

During our studies we discovered three novel chloro-demercuration reagents, viz. $\mathbf{S}_{\mathbf{2}} \mathbf{C l}_{\mathbf{2}}, \mathbf{S C l}_{\mathbf{2}}$, or (the least reactive) $\mathbf{S O}_{\mathbf{2}} \mathbf{C l}_{2}$. Mostly, they were applied as pure liquids, but for furan and thiophene mercurials, $\mathrm{S}_{2} \mathrm{Cl}_{2}$ had to be diluted with $\mathrm{CS}_{2}$ (Section 4). Thus, we obtained the following results:

i) 8-chlorocaffeine (90\%) from 8,8'-mercuriobis(caffeine), using neat liquid $\mathrm{S}_{2} \mathrm{Cl}_{2}$, or (70\%), using neat liquid $\mathrm{SCl}_{2}$, or $(27 \%)$ using neat liquid $\mathrm{SO}_{2} \mathrm{Cl}_{2}[1,2]$;

ii) 5-chlorouracil (65\%) from 5,5'-mercuriobis (uracil), using neat liquid $\mathrm{S}_{2} \mathrm{Cl}_{2}$ [4];

iii) 2-chlorofuran (60\%) from 2,2'-difurylmercury, using $\mathrm{S}_{2} \mathrm{Cl}_{2}$ diluted with $\mathrm{CS}_{2}$, or (50\%) from a mixture of furan and dry finely-powdered $\mathrm{HgCl}_{2}$ dissolved in excess $\mathrm{S}_{2} \mathrm{Cl}_{2}$ [5];

iv) 2-chlorothiophene (70\%) from 2,2'-dithienylmercury, using $\mathrm{S}_{2} \mathrm{Cl}_{2}$ diluted with $\mathrm{CS}_{2}$, or $(60 \%)$ from a mixture of thiophene and dry finely-powdered $\mathrm{HgCl}_{2}$ dissolved in excess $\mathrm{S}_{2} \mathrm{Cl}_{2}$ [5];

v) chlorobenzene (78\%) from diphenylmercury, using neat liquid $\mathrm{S}_{2} \mathrm{Cl}_{2}$, or $(69 \%)$ from (trifluoroacetoxymercurio)benzene, using neat liquid $\mathrm{S}_{2} \mathrm{Cl}_{2}$, or $(50 \%)$ from (acetoxymercurio)benzene, using neat liquid $\mathrm{S}_{2} \mathrm{Cl}_{2}$, or (47\%) from diphenylmercury, using neat liquid $\mathrm{SO}_{2} \mathrm{Cl}_{2}[5]$

vi) 5-chloro-1,3-dimethyluracil (74\%) from 5,5'-mercuriobis(1,3-dimethyluracil), using neat liquid $\mathrm{S}_{2} \mathrm{Cl}_{2}[8]$;

vii) 5-chloro-2,4-dimethoxypyrimidine (49\%) from 5,5`-mercuriobis(2,4-dimethoxypyrimidine), using neat liquid $\mathrm{S}_{2} \mathrm{Cl}_{2}$; the acid hydrolysis of pure 5-chloro-2,4-dimethoxypyrimidine afforded 5-chlorouracil (69\%) [9]. 


\subsection{Aromatic Fluorides from Aromatic Organomercurials}

By successively reacting (at ca $-60^{\circ} \mathrm{C}$ ) several symmetric organomercurials (vide infra) with a great excess of neat liquid $\mathbf{S F}_{4}$ (b.p. $-40.4^{\circ} \mathrm{C}$ ) the following monofluorinated products were obtained:

i) 8-fluorocaffeine (30\%) from 8,8'-mercuriobis(caffeine) [1,2];

ii) fluorobenzene (58\%) from diphenylmercury [12];

iii) 5-fluoro-1,3-dimethyluracil (30.3\%) from 5,5'-mercuriobis(1,3-dimethyluracil) [12];

iv) 5-fluoro-2,4-dimethoxypyrimidine (32.6\%) from 5,5'-mercuriobis(2,4-dimethoxypyrimidine); the former compound was demethylated to give 5-fluorouracil in $81.3 \%$ yield [12].

v) 5-fluorouracil (27.1\%) from 5,5'-mercuriobis(uracil) [12].

\subsection{Aromatic Nitriles from Aromatic Organomercurials}

i) 8-cyanocaffeine (50\% or $25 \%$, resp.) from either 8,8'-mercuriobis(caffeine) or 8-(acetoxymercurio) caffeine, with freshly purified $\mathbf{B r C N}$ in hot $\left(60^{\circ} \mathrm{C}\right)$ water $[1,2]$;

ii) benzonitrile (86\%) from diphenylmercury, with freshly purified $\mathbf{B r C N}$ in boiling dry benzene [7].

\section{Improved Syntheses of Some Diaryliodonium Salts from Symmetric Diarylmercurials and (Dichloroiodo)arenes (Willgerodt`s Method) [16]}

Willgerodt [70-72] had reacted cold (or hot [71]) aqueous suspensions of equal masses [in practical terms this means that the mercurials were used in a deficit] of powdered $\mathrm{PhICl}_{2}$ with powdered $\mathrm{Ar}_{2} \mathrm{Hg}$ (where $\mathrm{Ar}=$ phenyl, 2- and 4-tolyl, and 2-naphthyl) to afford the respective diaryliodonium chlorides (yields were not reported); sparingly soluble $\mathrm{ArHgCl}$ and other admixtures, e.g. PhIO [73], were hot-filtered off and discarded, viz.

\section{Scheme 15}

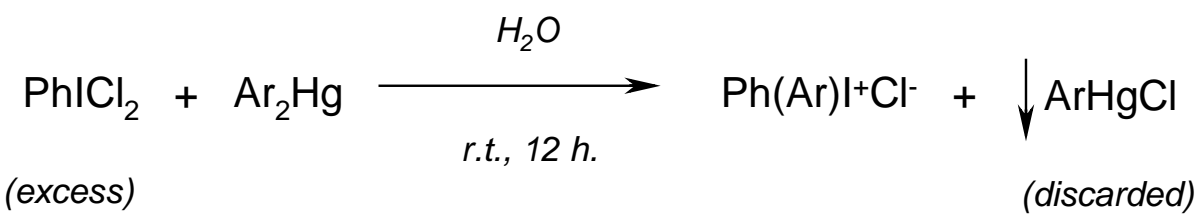

Beringer and Lillien [74] applied the Willgerodt method to obtain three unsymmetric diaryliodonium chlorides. They obtained only 4-acetamidophenyl(phenyl)iodonium chloride (which was precipitated out as its sparingly soluble iodide, isolated in $\mathbf{1 0 \%}$ crude yield) by reacting equimolar amounts of $\mathrm{Ph}_{2} \mathrm{Hg}$ with 4- $\mathrm{AcNHC}_{6} \mathrm{H}_{4} \mathrm{ICl}_{2}$ in hot water $\left(40-50^{\circ} \mathrm{C}\right)$ for 12 hours. We obtained [16] the same iodide, but in $\mathbf{8 0 \%}$ crude yield, by reacting equal masses of $\mathrm{PhICl}_{2}$ with symmetric 4,4- 
mercuriobis(acetanilide) suspended in stirred hot water $\left(40-50^{\circ} \mathrm{C}\right)$ for 12 hours. We explained this evident yield increase as follows:

\section{Scheme 16}

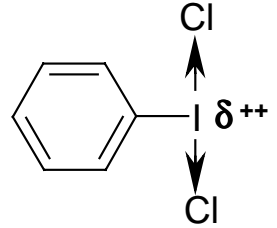

(more reactive)

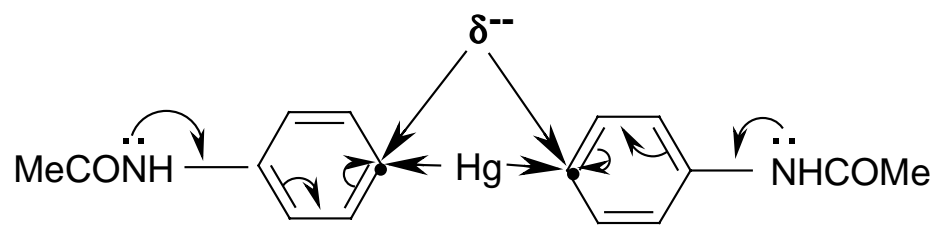

(more reactive)

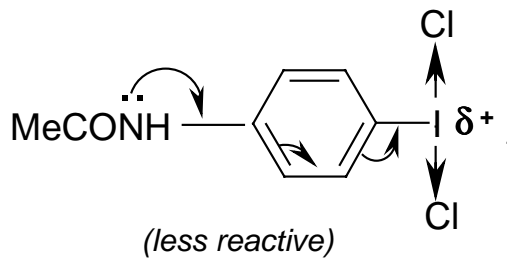

Electrophilic reagents

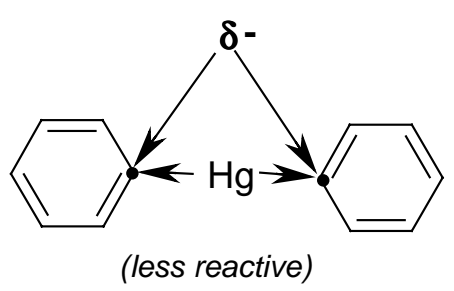

Nucleophilic reagents

Consequently, by reacting equal masses of $\mathrm{PhICl}_{2}$ with symmetric 4,4-mercuriobis $(N, N$ dimethylaniline), suspended in stirred hot water $\left(40-50^{\circ} \mathrm{C}\right)$ for 12 hours, we isolated from the hot filtrate, after its cooling, 4-dimethylaminophenyl(phenyl)iodonium chloride in $\mathbf{6 0 \%}$ crude yield. Previously, Beringer and Lillien [74] failed to obtain this iodonium salts, para-substituted with only one $\mathrm{NMe}_{2}$ group; the same failure was also reported by Neiland [75]. A similar iodonium salt bearing the two $p, p$ '-substituted $\mathrm{NMe}_{2}$ groups was synthesized by quite a different route [76]; this synthesis is shown (Scheme 7) in our paper [16].

We also attempted, without effect, to synthesize various 8-(aryliodonio)caffeine halides with using the Willgerodt method. Hence, we used our short-cut, oxidative method [77] to obtain 8-(4-methoxyphenyliodonio)caffeine bromide (49\% crude yield) by acidic coupling of the previously oxidized 8 -iodocaffeine with anisole. This is, in fact, the first iodine(III) derivative of caffeine, which may open up novel routes for preparing 8-substituted caffeines by its reactions with various nucleophiles [78].

\section{Conclusions}

This review shows our small research group's main interests in developing novel (or considerably improved) preparative procedures, mainly in the class of aromatic heterocyclic mercurials, which afforded a number of both unsymmetric, $\mathrm{ArHgX}$, and symmetric, $\mathrm{Ar}_{2} \mathrm{Hg}, \mathrm{C}$-mercurated compounds, mostly not reported in the former literature. In our opinion, most interesting are those indirect preparative C-mercuration methods, which made possible the syntheses of organomercurials derived from uracil, theophilline, and theobromine; they also open up new ways for preparing other similar 
organomercurials from many aromatic activated systems having $\mathrm{N}-\mathrm{H}$ acidic groups, which when reacted with mercuric salts, usually form at once the insoluble $\mathrm{N}-\mathrm{Hg}$ salts that precipitate out from the reaction mixtures, instead of forming the expected true organomercurials (with the mercury atoms joined to the organic residues via carbon atoms). In order to better confirm the chemical structures of the new organomercurials synthesized by us, they were next iodo- and/or bromo-demercurated (by known halo-demercuration procedures) to form in high yields a considerable number of the respective (purified) iodo and bromo derivatives (Section 13), whose structures were well established chemically, spectrally, and by comparison with the available literature data. We also discovered same novel haloand cyano-demercuration procedures, which enabled us to obtain a number of the corresponding (purified) aromatic halides and nitriles in high yields (Section 13). Also very interesting is our synthesis of 1,8-bis(acetoxydimercurio)theobromine, seemingly the first stable organic derivative of $\operatorname{mercury}(\mathbf{I})$, as well as its novel reactions (Section 11). Finally, we considerably improved the old Willgerodt method (1897), which enables to synthesize in high yields diaryliodonium chlorides from appropriate (dichloroiodo)arenes and symmetric aromatic organomercurials (Section 14). We hope that our preparative procedures, disscussed and explained in the present review, will be applied either as such, or they would be further improved and extended in other organic chemical laboratories.

\section{Acknowledgements}

Thanks are due to our dear Egyptian visitors, Doctors Mohammed Nabil Mohammed Khodeir and Ez-el-Din Kandeel, for their valuable contributions and helpful discussions. Our research was subsidized from funds administered by the Polish Academy of Sciences, which also is gratefully acknowledged.

\section{References}

A List of Our Papers and Ph. D. Theses on Heteroaromatic Organomercurials and Their Reactions:

1. Piotr Wroczynski, Ph.D. thesis entitled: "Some demercuration reactions of 8-acetoxymercurio- and 8,8'-mercuriobis-caffeines" [in Polish]; Fac. Of Pharmacy, Med. Acad., Warsaw 1981. Defended on Oct. 25, 1981.

2. Skulski, L.; Wroczynski, P. Some new halo- and cyano-demercuration reactions of 8acetoxymercurio- and 8,8'-mercuriobis-caffeines. Polish J. Chem. 1982, 56, 975-982.

3. Skul'ski, L.; Vrochin'ski, P. Bromo- and iodo-demercuration reactions of 8-acetoxymercurio derivatives of theophylline and theobromine (in Russian). Khim. Geterotsikl. Soed. 1983, 543-546.

4. Vrochin'ski, P.; Kuyava, A.; Skul'ski, L. Iodo- and chloro-demercuration reactions of 5,5'mercuriobis-uracil (in Russian). Khim. Geterotsikl. Soed. 1985, 386-389.

5. Khodeir, M. N. M.; Skulski, L.; Wroczynski, P. Preparation of 2-chlorofuran and 2chlorothiophene from the respective furan and thiophene mercurials and disulfur dichloride. Bull. Polish Acad. Sci., Chem. 1986, 34, 443-448. 
6. Anna Kujawa, Ph.D. thesis entitled: "Halo-demercuration reactions of mercurials derived from $N$ substituted uracils" [in Polish]; Fac. of Pharmacy, Med. Acad., Warsaw 1987. Defended on July $16,1987$.

7. Khodeir, M. N. M.; Skulski, L.; Wroczynski, P. Some new halo- and cyano-demercuration reactions of the benzene mercurials. Bull. Polish Acad. Sci., Chem. 1987, 35, 9-15.

8. Skulski, L.; Kujawa, A.; Kujawa, T. Halo-demercuration reactions of the 1,3-dimethyluracil and 1methyluracil 5-substituted mercurials. Bull. Polish Acad. Sci., Chem. 1987, 35, 499-505.

9. Skul'ski, L.; Kuyava, A.; Vrochin'ski, P. A new synthesis of 5-substiuted halogenouracils from corresponding 5-mercurio derivatives of 2,4-dimethoxypyrimidines (in Russian). Khim. Geterotsikl. Soed. 1989, 249-252.

10. Kandeel, Ez-el-Din; Skulski, L.; Wroczynski, P. Halo-demercuration reactions of 2,3-diphenyl-5methoxybenzo[b]furan mercurials. Bull. Polish Acad. Sci., Chem. 1990, 38, 37-40.

11. Niemyjska, M.; Skulski, L.; Zdrojewska, H. Direct aromatic mercuration by means of mercury(II) trichloroacetate prepared in situ. Bull. Polish Acad. Sci., Chem. 1990, 38, 41-46.

12. Skulski, L.; Kujawa, A.; Wroczynski, P. Fluoro-demercuration of some symmetric organomercurials by means of the liquefied, neat sulfur tetrafluoride. Bull. Polish Acad. Sci., Chem. 1991, 39, 23-28.

13. Baranowski, A.; Skulski, L. Novel syntheses of theobromine mercurials followed by their iodoand bromo-demercuration reactions. Bull. Polish Acad. Sci., Chem. 1991, 39, 29-35.

14. Skulski, L.; Baranowski, A.; Lempke, T. Further studies on some heterocyclic mercurials. Bull. Polish Acad. Sci., Chem. 1991, 39, 459-469.

15. Skulski, L.; and co-workers "A brief review of own works (1980-1992) on syntheses of some heterocyclic organomercurials and on their new reactions". XVth Intern. Conf. on Organometallic Chem. 1992, August 9-14, Warsaw, Poland; Abstracts, p. 92.

16. Skulski, L.; Wroczynski, P. Improved syntheses of some diaryliodonium salts from symmetric diarylmercurials and (dichloroiodo)arenes (Willgerodt method). Bull. Polish Acad. Sci., Chem. 1999, 47, 231-238.

Books and Reviews (or Valuable Comments) on Organomercurials and Their Reactions:

17. Whitmore, F. C. Organic Compounds of Mercury; Chem. Catalog Co.: New York, 1921.

18. Krause, E.; von Grosse, A. Chemie der metalloorganischen Verbindungen; Borntraeger: Berlin, 1937.

19. Coates, G. E. Organometallic Compounds; Methuen-Wiley: London-NewYork, 1956.

20. Rochow, E. G.; Hard, D. T.; Lewis, R. N. The Chemistry of Organometallic Compounds; WileyChapman \& Hall: New York-London, 1957; Russian transl.; Izd. Inostr. Lit.: Moskva, 1963.

21. Reutov, O. A. In Proc. of the XVIIth Int. Congress of Pure and Applied Chem., München, Aug. 30-Sept. 6, 1959; Butterworths-Verlag Chemie: London-Weinheim, 1960; Russian transl.; Izd. Inostr. Lit.: Moskva, 1963; pp 7-58. 
22. Harwood, J. H. Industrial Application of the Organometallic Compounds; Chapman \& Hall: London, 1963; Russian transl; Izd. Khimiya: Leningrad, 1970.

23. Nesmeyanov, A. N.; Makarova, L. G. Organic Compounds of Mercury; North Holland Publ. Co.: Amsterdam, 1967.

24. Jensen, F. R.; Rickborn, B. Electrophilic Substitution of Organomercurials; McGraw-Hill: New York, 1968.

25. Pauson, P. L. Organometallic Chemistry; Arnold, E., Ed., London, 1967; Russian transl.; Izd. Mir.: Moskva, 1970; Polish transl; PWN: Warsaw, 1972.

26. Makarova, L. G. In Organometallic Reactions; Becker, E. I.; Tsutsui, M., Eds.; Academic Press: Vol. 1, New York, 1970, pp 119-348; Vol. 2, New York, 1971, pp 355-423.

27. Reutov, O. A.; Beletskaya, I. P.; Sokolov, V. I. Mekhanizmy Reaktsii Metalloorganicheskikh Soedinenii; Izd. Khimiya: Moskva, 1972.

28. Zeller, K.-P.; Strauss, H.; Leditschke, H. In Houben-Weyl's Methoden der Organischen Chemie, 4th Ed., Vol.13 (2b), Mueller, E., Ed.; Thieme Verlag: Stuttgart, 1974.

29. Matteson, D. S. Organometallic Reaction Mechanisms of the Nontransition Elements; Academic Press: New York-London, 1974.

30. Larock, R. C. In New Applications of Organometallic Reagents in Organic Synthesis; Seyferth, D., Ed.; Elsevier: Amsterdam, 1976; J. Organomet. Chem. Library 1976, 1, 257.

31. Coates, G. E.; Green, M. L. H.; Powell, P.; Wade, K. Principles of Organometallic Chemistry; Chapman \& Hall: London, 1977.

32. Negishi, E. Organometallics in Organic Syntesis; Wiley-Interscience: New York, 1980; Vol. 1, Chapter 7.

33. Haiduc, I.; Zuckerman, J. J. Basic Organometallic Chemistry; de Gruyter: Berlin-New York, 1985; pp 74-79.

34. Larock, R. C. Organomercury Compounds in Organic Synthesis; Springer: New York, 1985, pp 60-97.

35. Butler, A. R. In Pizey Synthetic Reagents, Vol. 4; Wiley: New York, 1981, pp 1-45.

36. Wardell, J. L. In Zuckerman Inorganic Reactions and Methods, Vol. 11; VCH: New York, 1988, pp 308-318.

37. Thayer, J. S. Organometalic Chemistry: an Overwiew; Verlag Chemie: New York, 1988.

38. Organometallics in Organic Synthesis: Aspects of a Modern Interdisciplinary Field. de Meijere, A.; tom Dieck, H., Eds.; Proc. of the 1st Symp. on Organic Synthesis via Organometallics; Hamburg, Aug. 4-8, 1987; Springer: Berlin, 1988.

39. Advances in Organometallic Chemistry. Gordon, F.; Stone, A.; West, R.; Hill, A. F., Eds; Vols. 37-38; Academic Press: New York, 1995: Vol. 41; Academic Press: New York, 1997.

40. Advances in Metal-Organic Chemistry. Liebeskind, L. S., Ed.; JAI Press: Greenwich-London, 1995.

41. Wakefield, B. J. In Barton, D.; Ollis, W. D. Comprehensive Organic Chemistry. The Synthesis and Reactions of Organic Compounds; Jones, D. N., Ed.; Pergamon Press: Oxford, 1979; Vol. 3, pp 997-1012. 
42. (a) Nesmeyanov, A. N.; Kochechkov, K. A. Methods of Elementoorganic Chemistry; North Holland Publ. Co.: Amsterdam, 1967; Vol. 4; (b) Boev, V. I.; Moskalenko, A. I.; Boev, A. Advances in the field of methods for the synthesis of organomercury compounds (in Russian). Usp. Khim. 1997, 66, 874-900; (c) Casas, J. D.; Garcia-Tasende, M. S.; Sordo, J. Structural aspects of the coordination chemistry of organothallium(III) and organomercury(II) derivatives. Coord. Chem. Rev. 1999, 193-195, 283-359.

Other Papers on the Topic

43. Rosenthaler, L. Arch. Pharm. 1929, 266, 695.

44. Gomberg, M. Am. Chem. J. 1892, 14, 611.

45. Robins, R. K. In Heterocyclic Compounds. Elderfield, R. C., Ed.; Wiley: New York, 1967, Vol. 8, Chapter 3; see references submitted therein.

46. Fischer, E. Liebigs Ann. Chem. 1867, 215, 264.

47. Slotta, A. Ber. Dtsch. Chem. Ges. 1934, 67, 1028.

48. Fischer, E. Ber. Dtsch. Chem. Ges. 1898, 30, 2237.

49. Gomberg, A. J. Am. Chem. Soc. 1895, 17, 403.

50. Calmels, H. B. Compt. Rend. 1884, 99, 240.

51. Dreher, E.; Otto, R. Liebigs Ann. Chem. 1870, 154, 93.

52. Deacon, G. B.; Farquharson, G. J. Australian J. Chem. (a) 1976, 29, 627; (b) 1977, 30, 293 and 1701.

53. Krafft, F.; Lyons, R. E. Ber. Dtsch. Chem. Ges. 1894, 27, 1768.

54. Durrant, P. J.; Durrant, B. Introduction to Advanced Inorganic Chemistry. Longmans, Green: London, 1962; Polish transl.; PWN: Warsaw, 1965, p 941.

55. Grimmet, M. R. Adv. Heterocyclic Chem. 1993, 57, 291; 1993, 58, 271; 1994, 59, 245.

56. Gilman, H.; Wright, G. F. J. Am. Chem. Soc. 1933, 55, 3302.

57. Hartough, H. D. Thiophene and Its Derivatives: Interscience Publ.: New York-London, 1952.

58. (a) Hishmat, O. H.; Abd-el-Rahman, H. J. Pract. Chem. 1973, 315, 227; (b) Hishmat, O. H.; Abdel-Rahman, H. Australian. J. Chem. 1974, 27, 2499; (c) Hishmat, O. H.; Soliman, F. M.; Khalil, K. M. A. J. Pract. Chem. 1975, 317, 353.

59. Etzold, G.; Langen, P. Chem. Ber. 1965, 98, 1988.

60. Visser, G. W. M.; Diemer, E. L.; Kaspersen, F. M. J. Label. Comp. Radiopharm. 1980, 17, 657.

61. Jonas, J.; Gut, J. Coll. Czechoslov. Chem. Commun. 1962, 27, 716.

62. Dale, R. M. K.; Martin, E.; Livingston, D. C.; Ward, D. C. Biochemistry, 1975, 14, 2447.

63. Bergstrom, D. E.; Ruth, J. L. J. Am. Chem. Soc. 1976, 98, 1587.

64. Hilbert G. E.; Johnson, T. B. J. Am. Chem. Soc. 1930, 52, 2001; b) Whittaker, N. J. Chem. Soc. 1951, 1565.

65. Spector, L. B.; Keller, E. B. J. Biol. Chem. 1958, 232, 185.

66. Korn, A. P.; Ottensmeyer, F. P.; Jack, T. R. Inorg. Biochem. 1979, 10, 235. 
67. Bilt, A; Strufe, Z. Liebigs Ann. Chem. 1914, 404, 170; b) Knol, B. Friedl. 1912 - 1914, Vol. 11, p 962.

68. Casanova, J.; Rogers, H. R. J. Am. Chem. Soc. 1974, 96, 1942.

69. Bayer, I.; Posgay, E.; Majlat, P. Pharm. Zentralhalle, 1962, 101, 476.

70. Willgerodt, C. Die organischen Verbindungen mit mehrwertigem Jod; Enke Verlag: Stuttgart, 1914.

71. Willgerodt, C. Ber. Dtsch. Chem. Ges. 1897, 30, 56.

72. Willgerodt, C. Ber. Dtsch. Chem. Ges. 1898, 31, 915.

73. Freidlina, R. K.; Nesmeyanov, A. N. Compt. Rend. [Doklady] Acad. Sci. U. R. R. S. 1940, 29, 567; [Chem. Abstr. 1941, 35, 3614].

74. Beringer, F. M.; Lillien, I. J. Am. Chem. Soc. 1960, 82, 725.

75. Neiland, O. Ya. Latv. PSR Zinat. Akad. Vestis, Kim. Ser. 1964, 589; see p 591.

76. Beringer, F. M.; Chang, L. L. J. Org. Chem. 1972, 37, 1516.

77. Kazmierczak, P.; Skulski, L. Synthesis, 1995, 1027.

78. (a) Koser, G. F. Halonium Ions In The Chemistry of Functional Groups, Suppl. D.; Patai, S.; Rappoport, Z., Eds.; Wiley-Interscience: New York, 1983; Chapter 18; (b) Varvoglis, A. The Organic Chemistry of Polycoordinated Iodine; VCH: Weinheim, 1992.

Sample Availability: Not applicable

(C) 2001 by MDPI (http://www.mdpi.org). Reproduction is permitted for noncommercial purposes 